\title{
Yaşam Memnuniyeti Ölçeği’nin Geliştirilmesi ve Psikometrik Özellikleri
}

\author{
Mehmet Fatih KÖSE* $\quad$ Gözde ÇOBANOĞLU** Rahime MERCAN SARI ${ }^{* * * *}$
}

- Geliş Tarihi: 06.11.2021 • Kabul Tarihi: 04.02.2022 • Çevrimiçi Yayın Tarihi: 04.02.2022

\section{$\ddot{O} z$}

$\mathrm{Bu}$ araştırma, bireylerin yaşam alanlarından hareketle genel yaşam memnuniyetini belirlemeye yönelik bir ölçek geliştirmeyi amaçlamaktadır. Araştırmanın çalışma grubunu 629 lise ve 904 üniversite öğrencisi oluşturmuştur. Ölçeğin yapısal niteliklerini tespit etmek üzere açımlayıcı (AFA) ve doğrulayıcı faktör analizi (DFA) yapılmıştır. EFA sonuçları yaşam memnuniyetinin kişisel ve sosyal yaşam memnuniyeti, ekonomik yaşam memnuniyeti olmak üzere iki boyutta değerlendirilebileceğini göstermektedir. DFA sonuçları iki faktörlü yapının hem üniversite öğrencileri hem de lise öğrencileri için kabul edilebilir bir model uyumu gösterdiğini ortaya koymaktadır. Ayrıca ölçeğin ölçüt geçerliğine ve ayırt edici geçerliğine de sahip olduğu belirlenmiştir. Ölçeğin iç tutarlılık değerleri ise her iki grup için .7 değerinin üzerinde bulunmuştur. Araştırma sonuçlarına göre ekonomik yaşamdan memnuniyetin, yaşam memnuniyetini kişisel/sosyal yaşama göre yaklaşık dört kat daha fazla açıklama gücüne sahip olduğu belirlenmiştir. Araştırma sonuçları, Yaşam Memnuniyeti Ölçeği'nin farklı yaşam alanlarından hareketle kişinin genel yaşam memnuniyetini belirlemek amacıyla kullanılabilecek geçerli ve güvenilir bir ölçme aracı olduğuna yönelik güçlü kanıtlar ortaya koymaktadır.

Anahtar kelimeler: Yaşam alanları, yaşam doyumu, öznel iyi oluş, kişisel ve sosyal yaşam, ekonomik yaşam.

\section{Atıf}

Köse, M.F., Çobanoğlu, G., ve Mercan Sarı, R. (2022). Yaşam memnuniyeti ölçeği'nin geliştirilmesi ve psikometrik özellikleri. Pamukkale Üniversitesi Eğitim Fakültesi Dergisi, 55, 324346.doi:10.9779.pauefd. 1020012

\footnotetext{
* Dr., GSB Eğitim Araştırma ve Koordinasyon Genel Müdürlüğü, ORCID: 0000-0002-2297-8152, m.fatihkose@gmail.com

** Doktora Öğrencisi, Hacettepe Üniversitesi İstatistik Bölümü, ORCID: 0000-0001-6816-9329, gozde.cobanoglu@gsb.gov.tr

*** Doktora Öğrencisi, Hacettepe Üniversitesi Sosyoloji Bölümü, ORCID: 0000-0003-0262-8478, Rahime.SARI@gsb.gov.tr
} 


\section{Giriş}

Bireylerin genel olarak yaşamından veya özel olarak yaşamının belirli alanlarından memnuniyeti, kişisel mutluluğunun yanı sıra kişilerarası ilişkilerle ve genel toplumsal refahla da yakından ilişkilidir. Bireylerin mutluluğu, toplum refahının sağlanması noktasında önemli görüldüğünden politika belirleyiciler, toplumsal refahı ve yaşam memnuniyetini artırıcı kararlar için yaşam memnuniyeti ölçümlerini dikkate almaktadır. Bu çerçevede Ekonomik İşbirliği ve Kalkınma Teşkilatı (OECD) ve Avrupa Komisyonu (EC) gibi uluslararası kuruluşlar tarafından uzun yıllardır yaşam memnuniyeti ölçümleri yapılmakta ve yayınlanmaktadır (EC, 2019; OECD, 2021). Benzer şekilde Türkiye İstatistik Kurumu (TÜIK), 2003 yılından itibaren her yıl düzenli olarak bireylerin genel mutluluk algısını, memnuniyet düzeyini etkileyen faktörleri ve memnuniyetin zaman içindeki değişimini ölçmektedir (TÜIKK, 2021).

En genel anlamda, kişinin yaşam koşullarından hoşnut olmasını veya bu koşulları kabul etmesini ifade eden yaşam memnuniyeti kavramı (Sousa ve Lyubomirsky, 2001), sebep ve sonuçları bakımından sosyal bilimlerin pek çok alanında yoğun ilgi görmüş bir kavramdır. $\mathrm{Bu}$ çerçevede, yaşam memnuniyetini etkileyen faktörlere odaklanan geniş bir alanyazın bulunmaktadır (Arı ve Yıldız, 2016; Çebi Karaaslan, Çalmaşur ve Emre Aysin, 2021; Eygü ve Kılınç, 2020; Güven ve Şener, 2010; Ramachandiran ve Radhika, 2012). Bu çalışmalar; cinsiyet, yaş, medeni durum, eğitim durumu, sağlık düzeyi, gelir düzeyi, genetik, kişilik özellikleri, ekonomik refah seviyesi, güvenlik, sosyal hayat, aile ilişkileri, sevgi ve şefkat düzeyi gibi pek çok faktörün yaşam memnuniyeti üzerinde etkili olduğunu göstermektedir (Akdeniz, Aydemir, Akdeniz, Gülseren ve Kültür, 1999; Karagöz, Doğan ve Koçyiğit, 2016; Korkmaz, Germir, Mannell ve Dupuis, 2007; Şeker 2011; Yetim ve Çelik, 2020; Yücel ve Gürkan, 2015). Yaşam memnuniyetini belirleyen faktörlerin incelendiği araştırmaların yanı sıra yaşam memnuniyetinin bireyin yaşamındaki etkilerini belirlemeye yönelik araştırmalar da alanyazında önemli bir yer tutmaktadır (Lyubomirsky, King ve Diener, 2005; Schyns, 2002). Lyubomirsky ve arkadaşları (2005, s. 828), yaşam memnuniyeti yüksek olan bireylerin genel olarak daha sosyal, özgecil ve aktif oldukları, daha güçlü bedene ve bağışıklık sistemine sahip oldukları ve problem çözme becerilerinin daha fazla olduğu sonucuna ulaşmıştır. Benzer şekilde Beşel (2015)'in çalışmasında yaşam memnuniyeti yüksek olan illerde işsizlik oranının, boşanma hızının, elektrik tüketim miktarının ve nüfus yoğunluğunun yaşam memnuniyeti düşük olan illere göre daha az olduğu belirlenmiştir. Yaşam memnuniyetinin hem sebepleri hem de sonuçları itibariyle 

birey ve toplum yaşamı açısından önemli ve buna bağlı olarak sosyal bilimlerin çeşitli disiplinlerinde araştırmacıların yoğun ilgisini çeken bir olgu olduğu görülmektedir.

\section{Yaşam Memnuniyeti ve İlişkili Kavramlar}

Yaşam memnuniyeti, iyi bir yaşam için kriterler belirlemeyi, gerçek yaşamın bu kriterlere ne derece uyduğunu ve bu kriterlere ulaşmak için nelerin yapılması gerektiğini ortaya koymaya çalışan ve genel olarak yaşam kalitesi olarak adlandırılan daha geniş bir araştırma alanının parçası olarak da tarif edilmektedir (Veenhoven, 1996a, s. 11). Yaşam memnuniyeti veya yaşam doyumu, kişinin yaşam koşullarından hoşnut olmasını veya bu koşulları kabul etmesini ya da kişinin bir bütün olarak yaşamı için isteklerinin ve ihtiyaçlarının karşılanmasını ifade etmektedir. Diğer bir ifadeyle, kişinin kapsamlı bir şekilde yaşam kalitesini öznel olarak değerlendirmesidir (Sousa ve Lyubomirsky, 2001, s. 668). Alanyazında yaşam doyumu ve yaşam memnuniyeti kavramları genel olarak aynı anlamda kullanılmakta ve benzer şekilde ölçülmeye çalışılmaktadır. Yaşam doyumu kavramını ilk kez kullanan Neugarten, Havighurst ve Tobin (1961) kavramı, kişinin beklentileriyle sahip oldukları arasındaki farka odaklanarak ele almıştır. Yaşam doyumu veya yaşam memnuniyeti kavramları öznel iyi oluş hali çerçevesinde değerlendirilmektedir. Öznel iyi oluş kişinin kendi yaşamı hakkında bilişsel ve duyuşsal değerlendirme ve çıkarımlar yapmasını ifade ederken; yaşam doyumu/memnuniyeti öznel iyi oluşun bilişsel yönünü öne çıkarmaktadır (Diener, 1984). Öznel iyi oluşla ilgili çalışmalar yapan ve yaşam memnuniyetine ilişkin bir ölçek geliştiren Diener, Emmons, Larsen ve Griffen (1985), yaşam memnuniyetini yaşamın tüm boyutlarını değerlendirme biçimi olarak tanımlamaktadır. Duckworth, Seligman ve Steen (2005, s. 636) öznel iyi oluşun bileşenlerini olumlu duyguların varlığı, olumsuz duyguların yokluğu, bilişsel doyum ve tatmin yargısı olarak tarif etmektedir. Bu bakımdan Myers (2000, s. 60) ve Maddux (2018, s. 3-4) öznel iyi oluş çalışmalarında genellikle kişinin yaşamının nesnel koşulları ile o kişinin yaşamıyla ilgili öznel değerlendirmeleri ve duyguları arasında bir ayrım yapılması gerektiğini vurgulamaktadır. Bu bağlamda yaşam kalitesi nesnel ve öznel değerlendirme olarak ayrılmaktadır. Bireyin yaşam koşullarının gözlemlenebilir kriterlerini karşılama derecesi nesnel yaşam kalitesi çerçevesinde değerlendirilmekte ve bu objektif bir ölçüm yolunu ifade etmektedir. Öznel yaşam kalitesi ise insanların yaşamlarını öznel olarak nasıl değerlendirdiklerini içermektedir (Veenhoven, 1996b, s. 1). Yaşam memnuniyeti bu bağlamda bireyin yaşamına ilişkin öznel değerlendirmelerini ve tatminlerini içerdiğinden 
M.F., Köse, G, Çobanoğlu ve R.Mercan Sarı/ Pamukkale Üniversitesi Eğitim Fakültesi Dergisi, 55, 324-346, 2022327 yaşamın bütüncül ve bilişsel-yargılayıcı değerlendirilmesi olarak tanımlanmaktadır (Diener ve diğerleri, 1985).

Alanyazında yaşam alanı memnuniyeti ile yaşam memnuniyeti arasında da bir ayrım yapılmaktadır. Yaşam alanı memnuniyeti, bireyin yaşamının iş, evlilik ve gelir gibi belirli alanlarından duyduğu memnuniyeti ifade ederken; genel yaşam memnuniyeti, bireyin yaşamına ilişkin kapsamlı kanaatlerini ifade etmektedir ve yaşam alanı memnuniyetine göre çok daha geniş bağlamlıdır (Rojas, 2006; Sousa ve Lyubomirsky, 2001, s. 668). Yaşam alanları, yaşamın birçok özel alanını ifade etmektedir ve sınırlarını belirlemek kültürlere ve bireylere göre farklılık göstermektedir. Yaşamın farklı alanlarının genel yaşam doyumu üzerindeki etkisi genel olarak yaşam memnuniyeti araştırmalarında ele alınan bir boyut olmuştur (Barraca, Yarto ve Olea, 2000; Cummins, 1996, 1998, 2003; Dal ve Sevuktekin, 2018; McCamish-Svensson, Samuelsson, Hagberg, Svensson, Dehlin, 1999; Rojas, 2006; Veenhoven, 1996a; Zabriskie ve Ward, 2013). Mutluluğun belirleyicileri olarak tanımlanabilecek, kişilerin önem atfettiği yaşam alanları, bunların belirginliği ve önem düzeyi kültürlere göre değişiklik göstermekle birlikte bunlar için bir standart belirlemek de imkânsız değildir (Hofstede, Hofstede ve Minkov, 1991, s. 279). Bu bağlamda Cummins (1996) farklı yaşam alanlarını ve bunların yaşam memnuniyeti üzerindeki etkisini araştıran bir meta analiz çalışması yapmıştır. Analizler neticesinde maddi refah, sağlık, üretkenlik, yakınlık/samimiyet, güvenlik, duygusal refah ve topluluk olarak belirlediği yaşam alanları üzerinden yaşam memnuniyetinin ölçülebileceğini de ileri sürmüştür.

\section{Yaşam Memnuniyetinin Ölçülmesi}

Yaşam memnuniyeti kavramı ile bireyin yaşamdan memnun olma düzeyi, bunu belirleyen faktörler ve bundan etkilenen faktörler olmak üzere literatürde çeşitli ölçek geliştirme çalışmaları yer almaktadır. Bu alanda ilk ölçek çalışması olarak kabul edilen Yaşam Memnuniyeti Ölçeği (The satisfaction with life scale), Diener vd. (1985) tarafindan geliştirilmiştir. Söz konusu ölçeğin farklı gruplar için geçerlik ve güvenirlik çalışmaları da yapılmıştır (Diener, Pavot, Colvin ve Sandvik, 1991; Diener ve Pavot, 1993). Bu öncül çalışmaları takiben, literatürde farklı özelliklere sahip grupların yaşam memnuniyetini ölçebilmek için farklı ölçek geliştirme çalışmaları yer almıştır (Andrews ve Withey, 1976; Lavallee, Hatch, Michalos ve McKinley, 2007; Lightsey Jr, McGhee, Ervin, Gharghani, Rarey, Daigle, Wright, Powell, 2013; Mowrer ve Parker, 2004; Paolini, Yanez ve Kelly, 2006; Pavot, Diener ve Suh, 1998; Watson, Clark ve Tellegen, 1988). Özellikle ülkemizdeki yaşam memnuniyeti/doyumu ölçeklerinin, Diener ve diğerleri (1985), Lavallee ve diğerleri 
(2007), Huebner (1991) gibi araştırmacılar tarafindan geliştirilen yaşam memnuniyeti ölçeklerinin Türkçe uyarlanması ve farklı gruplara uygulanması yoluyla oluşturulmuş ölçekler olduğu görülmektedir (Akandere, Acar ve Baştuğ, 2009; Akın ve Yalnız, 2015; Altay ve Ekşi,2018; Çivitçi, 2007; Dağlı ve Baysal, 2016; Durak, Şenol-Durak ve Gençöz, 2010; Erol ve Yıldırım, 2016; Kaba, Erol ve Güç, 2018; Kaya, 2011; Köker, 1991; Yetim, 1993). Alanyazındaki bu uyarlama ölçek çalışmalarının yanı sıra ölçek geliştirme çalışmaları da bulunmaktadır (Özberk Ünsal, 2017; Tuzgöl-Dost, 2005; Ünsal ve Özalp Türetgen, 2005). Oldukça geniş bir literatür oluşturan ölçek geliştirme ve uyarlama çalışmaları, farklı disiplinlerin kendine özgü detayları ile ilgili daha derinlemesine sorgulamalar içermektedir. Örneğin eğitim alanında yapılan bir memnuniyet çalışması, öğretim programı, okul fiziki şartları gibi unsurları içerirken (Özberk Ünsal, 2017); sağlık alanında yapılmış bir çalışma, hasta ilişkileri ya da hastane fiziki şartları gibi unsurlara odaklanabilmektedir (Ercan, Ediz ve Kan, 2004).

Şeker (2011) yaşam alanlarını; sağlık, aile hayatı, güvenlik, eğitim ve sosyal hayat gibi alt alanlarla tanımlamış ve yaşam memnuniyetini bu alanlar üzerinden değerlendirmiştir. Akdeniz vd. (1999) ile Genç ve Karaman (2019) sağlıklı yaşam becerileri ve sağlık yaşamından memnuniyeti, Tezer (1996) evlilikten duyulan memnuniyeti, Taşdelen-Karçkay (2016) aile yaşamından duyulan memnuniyeti, Şahin (2009), Eygü ve Karaman (2013) ve Şahin, Göral, Demirel, Demirel ve Arslan (2014) eğitimden duyulan memnuniyeti, Çevik ve Korkmaz (2014) iş yaşamından duyulan memnuniyeti konu edinmiş ve bazıları buna yönelik ölçek geliştirme ya da uyarlama çalışmaları yapmıştır. Yapılan çalışmalarla ilgili genel bir değerlendirme yapıldığında, yaşam memnuniyetinin bağlama, kişiye ve topluma göre değişen dinamiklere sahip kültürel bir olgu olarak ele alındığı ve memnuniyet ölçümlerinde de bu dinamiklerin göz önünde bulundurulduğu görülmektedir.

Yukarıda ana hatları ile değinilen alanyazın incelendiğinde yaşam memnuniyeti çalışmalarının farklı yaş ve profildeki birey ve gruplara ya da belirli spesifik alanlardaki memnuniyete odaklandığı ve bunlara yönelik ölçek geliştirme çalışmalarının yapıldığ ifade edilebilir. İlgili alanyazın, yaşam alanlarındaki memnuniyet ile genel yaşam memnuniyeti arasında güçlü ilişkilerin varlığına işaret etmektedir (Dal ve Sevüktekin, 2018). Alanyazında yaşam alanlarının yaşam doyumuna etkisi bir inceleme konusu olmasına (Dal ve Sevüktekin, 2018; Rojas, 2006) ve özellikle istatistiki araştırmalarda (OECD, 2021; TÜİK, 2021) yaşam alanlarına dair memnuniyetin sıklıkla sorgulanmasına karşın bu ayrıma odaklı bir ölçek geliştirme çalışmasına rastlanamamıştır. Mevcut çalışma bu bağlamda, bireyin aile 
M.F., Köse, G, Çobanoğlu ve R.Mercan Sarı/ Pamukkale Üniversitesi Eğitim Fakültesi Dergisi, 55, 324-346, 2022329 yaşamı, sosyal yaşamı, ekonomik yaşamı, ruhsal yaşamı, sağlı yaşamı, eğitim yaşamı ve iş yaşamı gibi yaşam alanlarına ilişkin memnuniyet algılarından yola çıkarak genel yaşam memnuniyetine dair bir çıkarım ortaya koymayı amaçlayan bir ölçek geliştirme çalışması olup bu özelliği ile alanyazındaki diğer ölçek çalışmalarından farklılaşmaktadır. Rojas’a (2006) göre, yaşam alanları memnuniyeti ile yaşam memnuniyeti arasındaki ilişkilerin doğası ve bir alandaki memnuniyetin değişiminin diğer alanlardaki etkisi çok önemlidir. Bu bağlamda, yaşam alanlarına dayalı memnuniyet ölçümünün, politika yapıcı ve uygulayıcılar için, bireylerin yaşamlarına ilişkin memnuniyetlerinin ya da memnuniyetsizliklerinin hangi yaşam alanlarından kaynaklandığının bilinmesi ve pratik müdahale alanlarının tespit edilmesi bakımından da literatüre katkı sağlaması beklenmektedir. Yaşam memnuniyeti, sosyal ve kişisel yaşam alanlarındaki birçok faktörün etkileşimi ve/veya sonucu olarak ortaya çıkmaktadır. Dolayısıyla yaşam memnuniyetinin ölçülmesi, aile, okul ve iş hayatı gibi unsurların insan yaşamı üzerindeki sonuçlarının belirlenmesi açısından önem taşımaktadır. Bu çerçevede mevcut çalışma, bireylerin yaşam alanlarından hareketle yaşam memnuniyetini belirlemeye yönelik bir ölçek geliştirmeyi amaçlamaktadır.

\section{Yöntem}

\section{Çalışma Grupları}

Çalışma kapsamında, basit tesadüfi örnekleme yöntemi ile İstatistiki Bölge Birimleri Sınıflandırması (İBBS) 1'e göre 12 bölgede yaşayan 1533 lise ve üniversite öğrencisine ulaşılmıştır. Erikson'un psikososyal gelişim kuramına göre, 19 yaşa kadar olan dönem kimlik kazanmaya karşı kimlik karmaşası olarak tanımlanırken, 20 yaş sonrasında yakınlık kurmaya karşı yalıtılmışlık dönemi başlamaktadır (Erikson ve Erikson, 1998). Buna göre farklı psikososyal gelişim dönemlerinde olması beklenen bu iki grubun bilgi, beceri, alg1, tutum ve değerlerinde beklenen farklılaşmalara bağlı olarak, ölçeklerin geçerliliği ve güvenirliği gruplar için ayrı ayrı test edilmiş ve psikometrik özellikleri değerlendirilmiştir. Dolayısıyla bu çalışmada tüm analizler lise ve üniversite grupları için ayrı ayrı yürütülmüş ve raporlanmıştır. Katılımcıların demografik özellikleri Tablo 1'de gösterilmektedir. 


\section{Gruplar}

Demografik Özellikler

1. Grup

2. Grup

$\begin{array}{llll}\mathrm{n} & \mathrm{n}\end{array}$

Cinsiyet

Erkek

245

49.2

566

54.7

Kadın

253

50.8

469

45.3

Eğitim

Lise

226

45.4

403

39.0

Ön Lisans

116

23.3

253

24.4

Lisans ve üzeri

156

31.3

379

36.6

Toplam

498

100

1035

100

Tinsley ve Tinsley (1987) ölçek geliştirme çalışmalarında çalışma grubu büyüklüğünün madde sayısının en az beş ile on katı arasında olması gerektiğini belirtmektedir. $\mathrm{Bu}$ doğrultuda lise ve üniversite öğrencilerinden oluşan iki grup için de çalışma grubu büyüklüklerinin yeterli olduğu değerlendirilmiştir.

\section{İşlem Yolu ve Veri Analizi}

Çalışmanın ilk aşamasında, alanyazın incelemesi ve uzman görüşleri doğrultusunda, yaşam alanları teorileri temele alınarak, 50 maddelik bir soru havuzu oluşturulmuştur. DeVellis (2012) ölçek geliştirme çalışmalarında başlangıç aşamasındaki madde havuzunun nihai ölçek formunun 4-5 katı olmasının uygun olacağını ileri sürmektedir. Oluşturulan madde havuzu üzerinde; eğitim bilimci, sosyolog, psikolog ve ölçme değerlendirme uzmanlarından oluşan 12 kişilik bir uzman grubu ile odak grup çalışması yapılmıştır. Özdamar'a (2016) göre, teorik olarak karmaşık yapıda olmayan fenomenler için deneme ölçeğinin madde sayısının yüksek olması gerekmemektedir. Buna göre odak grup çalışması sonucunda benzer maddeler birleştirilmiş ya da ölçekten çıkarılmış ve 10 maddelik deneme ölçeğinin yaşam alanları için kapsam geçerliliğini sağlayacak yeterlilikte olduğuna karar verilmiştir. Hazırlanan ölçek, 5'li Likert tipi (Kesinlikle Katılmıyorum=1, Kesinlikle Katılıyorum=5) bir derecelendirmeye sahiptir. Birinci aşamada 498, ikinci aşamada ise 1035 olmak üzere 
M.F., Köse, G, Çobanoğlu ve R.Mercan Sar// Pamukkale Üniversitesi Eğitim Fakültesi Dergisi, 55, 324-346, 2022331 toplam 1533 lise ve üniversite öğrencisinin katılımı ile iki aşamalı bir saha uygulaması yapılmıştır. İlk aşamada, açımlayıcı faktör analizi (AFA) ile ölçeğin yapısal özellikleri incelenmiş ve üç maddenin birden fazla faktöre yakın yük verdiği $(x<.1)$ görülmüştür. Tekrar uzman görüşüne başvurularak, bu maddelerden ikisinin ölçekten çıkartılmasına, birisinin ise revize edilerek ölçekte tutulmasına karar verilmiştir. Yapılan revizyonlar sonrasında ikinci aşama veri toplama çalışması yapılmış ve ölçeğin yapısal özellikleri tekrar değerlendirilmiş ve Yaşam Memnuniyeti Ölçeği elde edilmiştir.

Araştırmanın veri toplama çalışması Covid-19 salgını nedeniyle çevrimiçi olarak gerçekleştirilmiştir. Verilerin analizinde SPSS 26 ve AMOS 26 programları kullanılmıştır. Analizlerden önce kayıp ve eksik veriler incelenmiş, z puanları +2 ile -2 aralığının dışında kalan uç veriler değerlendirme dişı bırakılmıştır. Buna göre veri setinin tekli ve çoklu normallik varsayımını karşılaması sağlanmıştır (Tabachnick ve Fidell, 2007). Veri setinin doğrusallık varsayımını karşılama durumun değerlendirmek üzere ise gözlenen değişkenler arasındaki saçılma grafikleri incelenmiştir. Değerlendirmeler sonucunda veri setinin temel varsayımlar olan doğrusallık ve normallik koşullarının sağlandığ1 görülmüştür. Buna göre ölçeğin yapısal özelliklerini test etmek için lise ve üniversite öğrencileri için ayrı ayrı AFA yapılmış ve elde edilen yapı DFA ile doğrulanmıştır. Verinin faktör analizine uygunluğunu tespit etmek için Kaiser-Meyer-Olkin (KMO) değeri ile Bartlett Küresellik test sonuçları incelenmiştir. AFA yapılırken faktörler arasındaki korelasyon .32'den fazla olduğunda eğik döndürme tercih edilmektedir (Tabachnick ve Fidell, 2007). Dolayısıyla bu çalışmada da eğik döndürme yöntemi tercih edilmiştir. Ölçeğin önemli faktör sayısının belirlenmesinde ise öz değer (eigen value) esas alınmış ve öz değeri 1'den büyük faktörler önemli faktör kabul edilmiştir (Büyüköztürk, 2007). Son olarak AFA ile yapısal özellikleri belirlenen yeni modeli test etmek amacıyla DFA yapılmış ve model uyumunu değerlendirmek üzere $x^{2} / \mathrm{sd}$. $<5$, normlaştırılmış uyum indeksi (NFI $\left.>.90\right)$, karşılaştırmalı uyum indeksi (CFI $\left.>.90\right)$, yaklaşık hataların ortalama karekökü $($ RMSEA<.08) ve iyilik uyum indeksi (GFI>.80) incelenmiştir (Gefen, Straub ve Boudreau, 2000; McDonald ve Ho, 2002). Ölçeğin güvenirlik çalışmaları kapsamında ise alt boyutlar arası korelasyon değerleri ile Cronbach alpha $(\alpha)$ iç tutarlılık katsayısı incelenmiştir. Çalışmanın yaşam memnuniyeti alanında yapmış olduğu ölçümün benzer bir kuramsal alandaki parametrelere göre ölçüm yapan benzer bir ölçekle korelasyonunu yani ilgili bir teorik yapı ile göstermiş olduğu benzerliği incelemek üzere ölçüt geçerliliği çalışması yapılmıştır. Bu kapsamda çalışmada Yaşam Doyumu Ölçeği kullanılmıştır. Söz konusu ölçek, Diener ve diğerleri (1985) tarafından 

geliştirilmiş, Dağlı ve Baysal (2016) tarafından Türkçeye uyarlanmıştır. Tek boyutlu beş maddeden oluşan ölçeğin model uyumu mükemmel düzeyde bulunmuştur $\left[\chi^{2} / \mathrm{sd}=1,17\right.$; RMSEA=.03; GFI=.99; CFI=1.00; NFI=.99]. Tek boyuta ilişkin iç tutarlılık değeri de .88 olarak tespit edilmiştir (Dağlı ve Baysal, 2016). Yaşam Doyumu Ölçeği’nin mevcut çalışma kapsamında da iç tutarlılığı incelenmiş ve .84 bulunmuştur. Çalışmada son olarak \%27'lik alt ve üst gruplar arasındaki farklılaşmayı değerlendirmek için gruplararası $t$-testi yapılmıştır.

\section{Bulgular}

Araştırmanın ilk aşamasında birinci grupta bulunan lise ve üniversite öğrencilerinin verilerine ayrı ayrı yapılan AFA sonuçları doğrultusunda birden fazla faktöre .1 değerinden daha yakın yük veren üç madde belirlenmiştir. Uzman görüşleri doğrultusunda bu üç maddeden ikisinin ölçekten çıkartılmasına, birinin ise düzenlenerek ölçekte tutulmasına karar verilmiştir. İkinci aşamada ise 8 maddeden oluşan ölçek 1035 (403 lise, 632 üniversite öğrencisi) katılımcıya uygulanmıştır. Uygulama sonuçlarına göre ölçeğin yapısal nitelikleri tekrar değerlendirilmiştir. Buna göre KMO değeri üniversite öğrencileri için .877 iken lise öğrencileri için .881 'dir. Bartlett Küresellik testi ise her iki grup için anlamlı $(p<.001)$ çıkmıştır. Bu sonuçlar doğrultusunda ölçeğin faktörel yapısını ve bileşenlerin açıklamış olduğu toplam varyansı tespit etmek üzere, AFA yapılmıştır. AFA sonuçları ile düzeltilmiş madde korelasyon katsayıları Tablo 2'de yer almaktadır.

AFA sonucunda Yaşam Memnuniyeti Ölçeği'nin hem lise hem üniversite grubu için iki faktörlü bir yapı gösterdiği ve bu iki faktörün toplam varyansın lise öğrencilerinde \%66.57'sini, üniversite öğrencilerinde \%66,17'sini açıklayabildiği görülmüştür. Birinci (2, $3,4,5)$ ve ikinci $(1,6,7,8)$ faktörün dört maddeden oluştuğu belirlenmiştir. Buna göre bireyin aile yaşamı, sosyal yaşam, ruhsal yaşamı ve sağlık yaşamı bir faktör altında toplanırken, ekonomik yaşamı, eğitim yaşamı, iş yaşamı ve hayat standartları başka bir faktör altında bir araya gelmiştir. Maddelerin teorik özellikleri incelenmiş ve uzman görüşleri doğrultusunda birinci faktörün kişisel/sosyal yaşamdan memnuniyet, ikinci faktörün ise ekonomik yaşamdan memnuniyet olarak adlandırılabileceğine karar verilmiştir. Madde toplam korelasyonlarının ise en düşük .537 olduğu görülmektedir. Field'e (2017) göre, .3 üzerindeki madde toplam korelasyonları güçlü kabul edilmektedir. 


\begin{tabular}{ccc}
\multicolumn{1}{c}{ Bileşenler } & $\begin{array}{c}\text { Düzeltilmiş } \\
\text { Madde }\end{array}$ \\
\cline { 1 - 1 } 1 & & $\begin{array}{c}\text { Korelasyon } \\
\text { Katsayıları }\end{array}$
\end{tabular}

1. Ekonomik durumumdan memnunum. $\quad .889(.934) \quad .620(.638)$

2. Aile yaşamımdan memnunum.

$.815(.768) \quad .579(.603)$

3. Sağlık durumumdan memnunum.

$.907(.894) \quad .552(.578)$

4. Sosyal hayatımdan memnunum.

$.584(.502) \quad .627(.663)$

5. Manevi yaşant

$.632(.767) \quad .635(.537)$

6. Hayat standartlarımdan memnunum.

$.894(.865)$

$.710(.691)$

7. Aldı̆̆ım eğitimin kalitesinden

$.743(.832)$

$.626(.597)$

memnunum.

8. İşimden memnunum.

$.768(.632)$

$.598(.612)$

$\begin{array}{lll}\text { Özdeğer } & 4.20(4.16) & 1.10 \\ & & (1.17) \\ \text { Açıklanan Varyans \% } & 52.45 & 13.72 \\ & (51.99) & (14.58)\end{array}$

Açıklanan Toplam Varyans \%

$66.17(66.57)$

Not: Parantez içindeki değerler lise öğrencilerine ait verilerdir.

AFA sonuçları doğrultusunda, AMOS programı kullanılarak, ölçeğin faktör yapısını doğrulamak üzere her iki gruba da DFA yapılmıştır. DFA sonuçları Şekil 1'de yer almaktadir. 

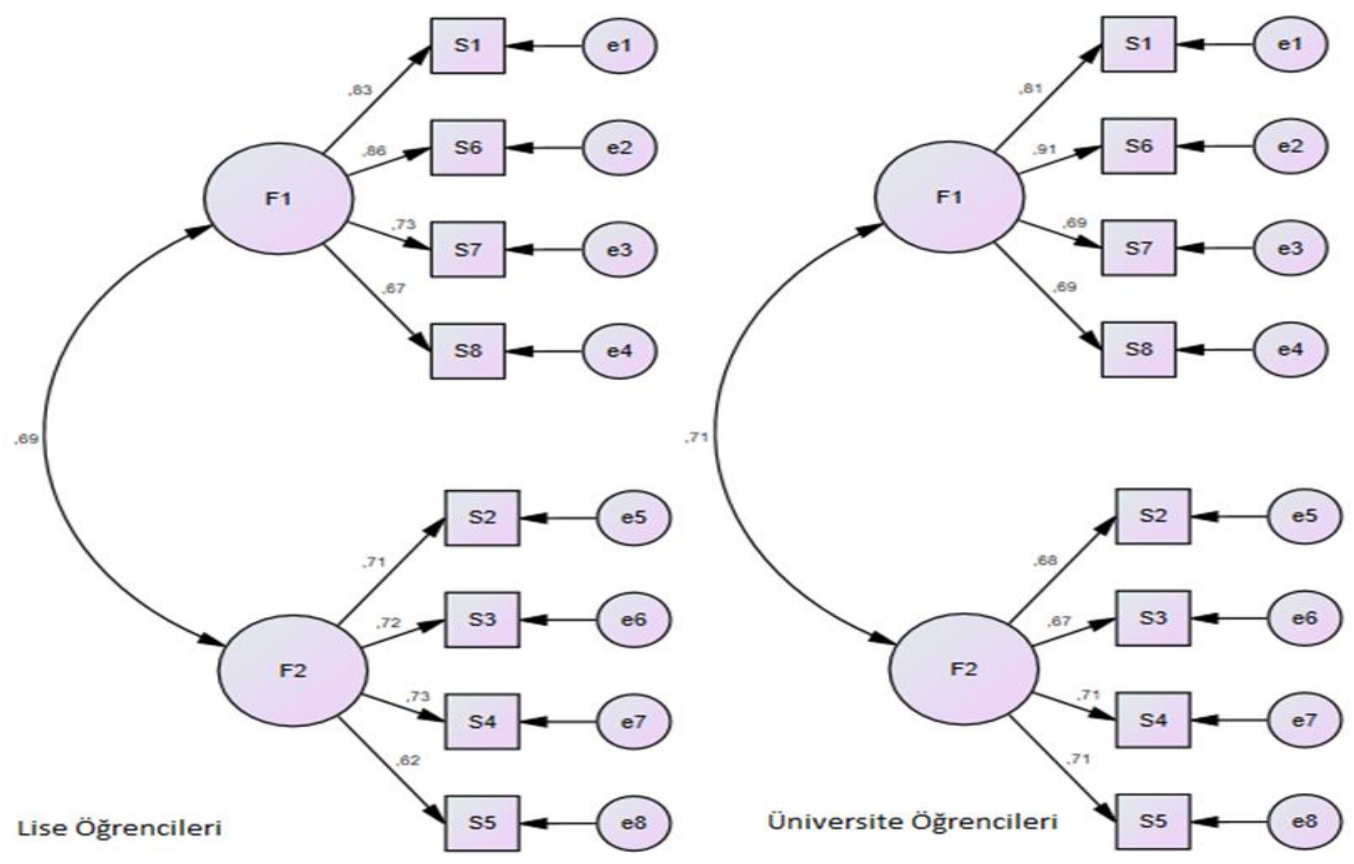

Şekil 1. Teorik Modele İlişkin DFA Sonuçları

Şekil 1 incelendiğinde, lise öğrencileri $\left[x^{2} / \mathrm{sd}=3,62 ; \mathrm{RMSEA}=.080 ; \mathrm{GFI}=.958\right.$; $\mathrm{CFI}=.964 ; \mathrm{NFI}=.951]$ ve üniversite öğrencilerinin $\left[x^{2} / \mathrm{sd}=4.93 ; \mathrm{RMSEA}=.079 ; \mathrm{GFI}=.962\right.$; $\mathrm{CFI}=.966$; NFI=.958] DFA sonuçları, iki faktörlü yapının her iki grup için kabul edilebilir bir model uyumu gösterdiğini ortaya koymaktadır.

Model uyumu doğrulanan iki faktörlü yapıya ilişkin iç tutarlık ve faktörler arası korelasyon değerleri Tablo 3'te yer almaktadır.

Tablo 3. Betimsel İstatistikler, Korelasyon ve Iç Tutarlılık Katsayıları

\begin{tabular}{lccccc}
\hline & $\bar{x}$ & SS & A & $\mathbf{1}$ & $\mathbf{2}$ \\
& 2.29 & .97 & $.86(.86)$ & 1 & \\
1. Tüm Ölçek & $(2.50)$ & $(1.06)$ & & & \\
& & & & & \\
2.Kişisel/Sosyal Yaşamdan & 1.73 & .96 & & $.87 *$ & \\
Memnuniyet & $(1.94)$ & $(1.10)$ & $.85(.84)$ & $\left(.87^{*}\right)$ & \\
& & & & & \\
3. Ekonomik Yaşamdan Memnuniyet & 2.85 & 1.21 & & $.92^{*}$ & $.69 *$ \\
& $(3.05)$ & $(1.28)$ & & $(.91 *)$ & $(.79 *)$
\end{tabular}

$* \mathrm{p}<.001 \quad * *$ Parantez içindeki değerler lise öğrencilerine ait verilerdir. 
M.F., Köse, G, Çobanoğlu ve R.Mercan Sarı/ Pamukkale Üniversitesi Eğitim Fakültesi Dergisi, 55, 324-346, 2022335

Tablo 3'te, faktörlerin alpha $(\alpha)$ iç tutarlılık katsayılarının .75'in üzerinde kabul edilebilir bir düzeyde olduğu görülmektedir (Özdamar, 2016). Faktörler arası korelasyon değeri ise lise öğrencileri için .71 iken üniversite öğrencileri için .69'dur.

Faktörler arasındaki ilişki istatistiki olarak anlamlı olmakla birlikte çoklu bağlantı sorunu görülmemektedir (Büyüköztürk, 2007). Değişkenler arası ilişkinin .9 üzerinde olması iki değişkenin aynı ölçümü yapıyor olabileceğini ve bazılarının gereksiz olabileceğini göstermektedir (Tabachnick ve Fidell, 2007). Buna göre araştırmanın gözlenen değişkenleri arasında tekillik ve çoklu bağlantı durumunu daha ayrıntılı incelemek üzere ölçek maddelerini oluşturan gözlenen değişkenler arasındaki ilişkiler incelenmiştir. Korelasyon sonuçları Tablo 4'te gösterilmektedir.

Tablo 4. Ölçek Maddeleri Arasındaki İlişkiler

\begin{tabular}{|c|c|c|c|c|c|c|c|c|c|}
\hline & $\bar{x}$ & SS & 1 & 2 & 3 & 4 & 5 & 6 & 7 \\
\hline $\begin{array}{l}\text { 1. Ekonomik } \\
\text { Durum }\end{array}$ & $\begin{array}{c}1,54 \\
(1.77)\end{array}$ & $\begin{array}{c}1.02 \\
(1.23)\end{array}$ & 1 & & & & & & \\
\hline $\begin{array}{l}\text { 2. Aile } \\
\text { Hayatı }\end{array}$ & $\begin{array}{c}2.98 \\
(3.14)\end{array}$ & $\begin{array}{c}1.59 \\
(1.68)\end{array}$ & $.353 *$ & 1 & & & & & \\
\hline $\begin{array}{l}\text { 3. Sağlik } \\
\text { Durumu }\end{array}$ & $\begin{array}{c}3.48 \\
(3.48)\end{array}$ & $\begin{array}{c}1.58 \\
(1.61)\end{array}$ & $.288^{*}$ & $.530 *$ & 1 & & & & \\
\hline $\begin{array}{l}\text { 4. Sosyal } \\
\text { Hayat }\end{array}$ & $\begin{array}{c}2.31 \\
(2.56)\end{array}$ & $\begin{array}{c}1.45 \\
(1.56)\end{array}$ & $.453 *$ & $.465^{*}$ & $.500 *$ & 1 & & & \\
\hline $\begin{array}{l}\text { 5. Manevi } \\
\text { Hayat }\end{array}$ & $\begin{array}{c}2.64 \\
(3.02)\end{array}$ & $\begin{array}{c}1.56 \\
(1.69)\end{array}$ & $.359 *$ & $.482 *$ & $.479 *$ & $.448 *$ & 1 & & \\
\hline $\begin{array}{l}\text { 6. Hayat } \\
\text { Standartları }\end{array}$ & $\begin{array}{c}1.69 \\
(1.92)\end{array}$ & $\begin{array}{c}1.11 \\
(1.29)\end{array}$ & $.736^{*}$ & $.385^{*}$ & $.349 *$ & $.536^{*}$ & $.428^{*}$ & 1 & \\
\hline $\begin{array}{l}\text { 7. Eğitim } \\
\text { Hayatı }\end{array}$ & $\begin{array}{c}1.75 \\
(1.78)\end{array}$ & $\begin{array}{c}1.16 \\
(1.25)\end{array}$ & $.578 *$ & $.378^{*}$ & $.305^{*}$ & $.429 *$ & $.401 *$ & $.616^{*}$ & 1 \\
\hline $\begin{array}{l}\text { 8. çalışma } \\
\text { hayatı }\end{array}$ & $\begin{array}{c}1.94 \\
(2.30)\end{array}$ & $\begin{array}{c}1.33 \\
(1.56)\end{array}$ & $.545^{*}$ & $.368^{*}$ & $.336^{*}$ & $.432 *$ & $.409 *$ & $.595^{*}$ & $.493^{*}$ \\
\hline
\end{tabular}

$* \mathrm{p}<.001 \quad * *$ Parantez içindeki değerler lise öğrencilerine ait verilerdir.

Maddeler arası korelasyonlar incelendiğinde, en yüksek ilişki hayat standartları ile ekonomik durum arasında (.736) gözlemlenirken, en düşük ilişki ise sağlık durumu ile 

ekonomik yaşam arasında (.288) görülmektedir. Buna göre .9 üzerinde bir korelasyon oluşmadığı için çoklu bağlantı sorunu görülmemektedir. Bütün yaşam alanları arasında pozitif yönlü doğrusal bir ilişki olması yaşam alanlarındaki memnuniyetlerin bir araya gelme eğiliminde olduğunu gösterir. Genel olarak, bir kişinin bazı yaşam alanlarındaki memnuniyetinin olumlu ya da olumsuz yönde birlikte değişim gösterme eğiliminde olduğu yorumu yapilabilir.

Ölçeğin teorik kapsamının geçerliliğini test etmek üzere ölçüt geçerliği çalışması yapılmıştır. Buna göre teorik yapının benzerliği nedeniyle, Yaşam Doyumu Ölçeği (Diener vd., 1985) ölçüt geçerliliği için benzer ölçek olarak kullanılmıştır. Ölçeğin, Yaşam Doyumu Ölçeği ile korelasyonları Tablo 5'te sunulmaktadır.

Tablo 5. Yaşam Doyumu Ölçeği ile Yaşam Memnuniyeti Ölçeğinin Korelasyon Analizi

\begin{tabular}{lccc}
\hline & 1 & 2 & 3 \\
\hline 1. Yaşam Doyumu & 1 & .651 & .526 \\
2. Kişisel/Sosyal Yaşam & & 1 & .503 \\
3. Ekonomik Yaşam & & & 1 \\
\hline
\end{tabular}

Ölçüt geçerliği, bir yapının ilgili diğer yapılarla teorik olarak ilişkili olduğunu göstermektedir (DeVellis, 2012). Tablo 5 incelendiğinde, Yaşam Doyumu Ölçeği ile Yaşam Memnuniyeti Ölçeğinin alt boyutları arasında pozitif yönlü anlamlı bir ilişkiler ölçüt geçerliliğinin bir kanıtı olarak görülmüştür.

Son olarak ölçeğin ayırt ediciliğini değerlendirmek üzere \%27'lik alt ve üst gruplar arasındaki farklılaşmayı değerlendirmek için gruplararası $t$-testi yapılmıştır. Test sonuçları Tablo 6'da yer almaktadır. Tablo 6' da yer alan analiz sonuçlarına göre, alt ve üst gruplar arası farkın anlamlı olması $\left(t_{\min }=-33.36 ; \mathrm{p}>.001\right)$ tüm ölçek ve alt faktörler için ölçeğin ayırt edicilik gücünün yüksek olduğunu göstermektedir. 
M.F., Köse, G, Çobanoğlu ve R.Mercan Sarı/ Pamukkale Üniversitesi Eğitim Fakültesi Dergisi, 55, 324-346, 2022337 Tablo 6. Alt ve Üst Gruplar Arası Farklılaşma

\begin{tabular}{|c|c|c|c|c|c|}
\hline & Gruplar & $\bar{x}$ & SS & $t$ & $\mathbf{p}$ \\
\hline \multirow{3}{*}{ Tüm Ölçek } & Alt & 1.21 & .208 & \multirow{3}{*}{-66.20} & \multirow{3}{*}{.000} \\
\hline & & & & & \\
\hline & Üst & 3.70 & .594 & & \\
\hline \multirow{3}{*}{ Kişisel/Sosyal Yaşamdan Memnuniyet } & Alt & 1.38 & .407 & \multirow{3}{*}{-65.67} & \multirow{3}{*}{.000} \\
\hline & & & & & \\
\hline & Üst & 4.32 & .628 & & \\
\hline \multirow{3}{*}{ Ekonomik Yaşamdan Memnuniyet } & Alt & 1.03 & .120 & \multirow{3}{*}{-33.36} & \multirow{3}{*}{.000} \\
\hline & & & & & \\
\hline & Üst & 3.08 & 1.016 & & \\
\hline
\end{tabular}

\section{Puanlama}

Ölçekte iki alt boyutta toplam sekiz madde yer almakta olup ters puanlanması gereken madde bulunmamaktadır. Kişisel/sosyal yaşamdan memnuniyet alt boyutu 2., 3., 4. ve 5. maddeleri, ekonomik yaşamdan memnuniyet alt boyutu ise 1., 6., 7. ve 8. maddeleri içermektedir. Toplam ölçek puanları 8 ile 40 arasında değişmektedir. Yüksek puan, daha yüksek yaşam memnuniyetine işaret etmektedir. Bu çalışmada katılımcılar tarafından elde edilen puanlar 8 ila $40(\bar{x}=18.97, \mathrm{sd}=8.09)$ aralığında değişmektedir.

\section{Tartışma, Sonuç ve Öneriler}

Mevcut çalışma kapsamında bireyin yaşam alanlarına ilişkin memnuniyet algılarından yola çıkarak genel yaşam memnuniyetini değerlendirmek üzere bir ölçek geliştirme çalışması yapılmıştır. Ölçeğe ilişkin geçerlik ve güvenirlik çalışmaları, Yaşam Memnuniyeti Ölçeği 'nin araştırmacı ve uygulamacılar tarafından kullanılabilecek geçerli ve güvenilir bir ölçme aracı olduğuna yönelik güçlü kanıtlar ortaya koymuştur.

Ölçeğin faktör yapısına ilişkin teorik ve istatistiki değerlendirmeler, genel yaşam memnuniyetinin değerlendirilmesinde, kişisel sosyal yaşamdan memnuniyet ve ekonomik yaşamdan memnuniyet olmak üzere iki faktörlü bir model kullanılabileceğini göstermiştir. Belirlenen kavramsal model, istatistiki olarak güçlü bir model uyumu göstermiştir. Her iki alt faktörün iç tutarlılık değerleri kabul edilebilir sınırların üzerinde bulunmuştur. Kişisel ve 

sosyal yaşam memnuniyeti, bireyin aile ve sosyal ilişkileri ile sağlik ve manevi (spiritual) yaşamından memnuniyetini ifade ederken; ekonomik yaşamdan memnuniyet bireyin eğitim ve iş memnuniyeti ile genel ekonomik durumundan ve hayat standartlarından memnuniyetini ifade etmektedir. Araştırma bulguları, sosyal/kişisel hayat memnuniyeti ile ekonomik yaşam memnuniyeti arasında güçlü ve anlamlı bir ilişki olduğunu ortaya koymaktadır. Alt bileşenlere ilişkin açıklanan varyanslar incelendiğinde ise ekonomik yaşam memnuniyetinin genel yaşam memnuniyetini açıklama gücünün kişisel ve sosyal yaşam memnuniyetine göre yaklaşık dört kat daha yüksek olduğu görülmektedir. Bu önemli bulgu, ekonominin bireyin yaşamın alanları üzerindeki belirleyici ve güçlü etkisini de göstermektedir. Rojas'ın (2006) yaşam alanlarından memnuniyet ile yaşam memnuniyeti arasındaki ilişkinin doğasını incelediği dikkat çekici çalışması da bazı alanların genel yaşam memnuniyeti üzerinde daha etkili olduğunu göstermektedir. Vanderweele’ye göre (2017), yaşamın aile, iş, sağlık, topluluk ve maneviyat gibi farklı alanları birbirleriyle etkileşim içerisindedir ve bireyler bu alanlar arasında bir denge sağlamaktadır. Bu bağlamda, farklı sosyoekonomik düzeylerde ekonomik yaşam memnuniyeti ile yaşamın kişisel ve sosyal alanlarından memnuniyet arasındaki ilişkilerin değerlendirilmesine yönelik daha ileri çalışmalar yapılması önerilebilir.

Kişisel/sosyal yaşam ve ekonomik yaşam olmak üzere iki temel bileşen çerçevesinde değerlendirilen alt alanlar, ölçeğin teorik kapsamını oluşturan yaşam alanları literatürünün ortaya koyduğu; aile, sağlık, eğitim, iş, ekonomi, sosyal hayat gibi temel alanları (Cummins, 1996; Dal ve Sevuktekin, 2018; Rojas, 2006; Sousa ve Lyubomirsky, 2001; Vanderweele, 2017) kapsamına almaktadır. Yaşam alanları arasındaki sınırların kültürel bağlama göre farklılaştığı göz önüne alındığında (Hofstede vd., 1991), bu araştırmanın çalışma grubunu oluşturan lise ve üniversite gençleri açısından eğitim, iş ve ekonomi ile ilgili faktörlerin benzer psikolojik dinamiklerde yorumlandığı söylenebilir. Bireysel, sosyal, politik ve ekonomik pek çok işlevi olan eğitimin, ekonomik yaşamın bir unsuru olarak algılanması araştırmanın önemli bir bulgusudur. Özellikle üniversite öğrencilerinin eğitimden en önemli beklentilerinin iyi bir iş ve ekonomik gelir olduğunu gösteren (Korukoğlu, 2003) bulgularla birlikte değerlendirildiğinde, eğitimde pragmatist bir anlayışın öne çıktığı ileri sürülebilir. $\mathrm{Bu}$ anlayış, kapitalist eğitim eleştirileri bağlamında, bireylerin eğitime yükledikleri anlam ve değeri, yetkin ve özgür bireyler olarak kendini gerçekleştirme yerine iş piyasasındaki konumlarına veya toplumsal statülerine hapsettiği (Ünal, 2011), insanlara yararlı olma gibi toplumsal bağlarından kopararak ekonomik önceliklerle sınırlandırdığı (Güllüpınar, 2017) 
M.F., Köse, G, Çobanoğlu ve R.Mercan Sarı/ Pamukkale Üniversitesi Eğitim Fakültesi Dergisi, 55, 324-346, 2022339 tartışmalarına dikkat çekmektedir. Lise ve üniversite öğrencilerine odaklı ampirik verilerle sınırlı olan mevcut çalışma bulgularından hareketle, eğitim politikalarının yapılandırılmasında, ekonomik önceliklerin ötesinde toplumsallaşma, topluma yararlı olma ve kendini gerçekleştirme gibi üst düzey değerlere odaklı bir eğitim felsefesinin öne çıkarılması gerektiği söylenebilir.

Mevcut ölçek geliştirme çalışması, alanyazında yaygın olarak kullanılan spesifik alanlarla sınırlı memnuniyet ölçeklerine (Ercan, Ediz ve Kan, 2004; Özberk Ünsal, 2017; Ünsal ve Özalp Türetgen, 2005) bir alternatif oluşturabilir. Bu bağlamda geçerlik ve güvenirlik kanıtları sunulan Yaşam Memnuniyeti Ölçeği’nin araştırmacı ve uygulamacılar tarafından, farklı yaşam alanlarından hareketle kişinin genel yaşam memnuniyetini belirlemeye yönelik bir ölçme aracı olarak kullanılması önerilebilir. Araştırmanın örneklemle ilgili sınırlılığı nedeniyle, özelikle farklı sosyoekonomik düzeylerde ölçeğin yapısal özelliklerinin farklılaşma durumu ampirik olarak test edilmemiştir. Ayrıca, araştırmanın veri toplama çalışması Covid-19 salgını nedeniyle çevrimiçi olarak gerçekleştirildiği için test-tekrar test güvenirliği de yapılamamıştır. Daha ileri araştırmalarda ölçeğin yapısal özellikleri tekrar incelenebilir ve farklı yaş grupları ve sosyoekonomik sosyokültürel gruplar için yapısal nitelikleri test edilebilir.

Etik Kurul İzin Bilgisi: Bu araştırma, Gençlik ve Spor Bakanlı̆̆ı Bilimsel Araştırma ve Yayın Etik Kurulu'nun 03/09/21 tarihli ve 917650 sayıl izniyle yürütülmüştür.

Yazar Çıkar Çatışması Bilgisi: Yazarlar bu çalışmada çıkar çatışması olmadığını beyan ederler.

Yazar Katkısı: Tüm yazarlar çalışmaya anlamlı düzeyde katkı să̆lamış olup çalışmanın içeriği üzerinde mutabık kalmışlardır. 


\section{Kaynaklar}

Akandere, M., Acar, M. ve Baştuğ, G. (2009). Zihinsel ve fiziksel engelli çocuğa sahip anne ve babaların yaşam doyumu ve umutsuzluk düzeylerinin incelenmesi. Selçuk Üniversitesi Sosyal Bilimler Enstitüsü Dergisi, 22(1), 23-32.

Akdeniz, C., Aydemir, Ö., Akdeniz, F., Gülseren, Ş. ve Kültür, S. (1999). Sağl1k Düzeyi Ölçeği’nin Türkçeye uyarlanması ve güvenilirliği. Klinik Psikofarmakoloji Bülteni, 9(2), 104-108.

Akın, A. ve Yalnız, A. (2015). Yaşam Memnuniyeti Ölçeği (YMÖ) Türkçe formu: Geçerlik ve güvenirlik çalışması. Elektronik Sosyal Bilimler Dergisi, 14(54), 95-102. https://doi.org/10.17755/esosder.68461

Altay, D. ve Ekşi, H. (2018). Çocuklar için yaşam doyum ölçeği geçerlilik güvenilirlik çalışması. 5. Uluslararası Eğitim Bilimleri Sempozyumu'nda sunulan tam metin bildiri (s. 354-362), İstanbul, Türkiye.

Andrews, F. A. ve Withey, S. B. (1976). Social indicators of well being: Americans' perceptions of life quality. Plenum.

Arı, E. ve Yıldız, Z. (2016). Bireylerin yaşam memnuniyetini etkileyen faktörlerin sıralı lojistik regresyon analizi ile incelenmesi. Journal of International Social Research, 9(42):1362-1362.

Barraca, J., Yarto, L. L. ve Olea, J. (2000). Psychometric properties of a new family life satisfaction scale. European Journal of Psychological Assessment, 2, 98-106.

Beşel, F. (2015). 2013 yılı yaşam memnuniyeti araştırması sonuçlarının il bazlı ekonomik, sosyal ve siyasi analizi. Karabük Üniversitesi Sosyal Bilimler Enstitüsü Dergisi, 5(2), 227-236.

Büyüköztürk, Ş. (2007). Sosyal bilimler için veri analizi el kitabı. Pegem.

Cummins, R. A. (1996). The domains of life satisfaction: An attempt to order chaos. Social Indicators Research, 38, 303-332.

Cummins, R. A. (1998). Directory of instruments to measure quality of life and cognate areas. Melbourne: School of Psychology, Deakin University.

Cummins, R. A. (2003). A model for the measurement of subjective well-being through domains. Melbourne: School of Psychology, Deakin University. 
M.F., Köse, G, Çobanoğlu ve R.Mercan Sarı/ Pamukkale Üniversitesi Eğitim Fakültesi Dergisi, 55, 324-346, 2022341

Çebi-Karaaslan, K., Çalmaşur, G. ve Emre-Aysin, M. (2021), Bireylerin yaşam memnuniyetlerini etkileyen faktörlerin incelenmesi. Atatürk Üniversitesi İktisadi ve İdari Bilimler Dergisi, 35(1), 263-290. https://doi.org/10.16951/atauniiibd.789275

Çevik, N. K. ve Korkmaz, O. (2014). Türkiye'de yaşam doyumu ve iş doyumu arasındaki ilişkinin iki değişkenli sıralı probit model analizi. Niğde Üniversitesi İktisadi ve İdari Bilimler Fakültesi Dergisi, 7(1) , 126-145.

Çivitci, A. (2007). Çok boyutlu öğrenci yaşam doyumu ölçeğinin Türkçeye uyarlanması: geçerlik ve güvenirlik çalışmaları. Eurasian Journal of Educational Research, 26, 51-60.

Dağl1, A. ve Baysal, N. (2016). Yaşam doyumu ölçeğinin Türkçeye uyarlanması: geçerlik ve güvenirlik çalışması. Elektronik Sosyal Bilimler Dergisi, 15(59), 1250-1262. https://doi.org/10.17755/esosder.263229

Dal, S. ve Sevüktekin, M. (2018). Türkiye'de öznel iyi oluşun yaşam alanları yaklaşımı ile ölçülmesi. Uluslararası İktisadi ve İdari İncelemeler Dergisi, 18. EYİ Özel Sayısı, 433-446. https://doi.org/10.18092/ulikidince.351465

DeVellis, R. F. (2012). Scale development: Theory and applications. Sage.

Diener, E. (1984). Subjective well being. Psychological Bulletin, 95(3), 542-575.

Diener, E. ve Pavot, W. G. (1993). Review of the satisfaction with life scale. Psychological Assessment, 5, 164-172.

Diener, E., Emmons, A. R., Larsen, J. R. ve Griffin, S. (1985). The satisfaction with life scale. Journal of Personality Assessment, 49(1), 71-75.

Diener, E., Pavot, W. G., Colvin, C. R. ve Sandvik, E. (1991). Further validation of the satisfaction with life scale: Evidence for the cross-method convergence of well-being measures. Journal of Personality Assessment, 57, 149-161.

Duckworth, A. L., Steen, T. A. ve Seligman, M. E. (2005). Positive psychology in clinical practice. Annual Review of Clinical Psychology, 1, 629-651.

Durak, M., Şenol-Durak, E. ve Gençöz, T. (2010). Psychometric properties of the satisfaction with life scale among Turkish university students, correctional officers, and elderly adults. Social Indicators Research, 99(3), 413-429. https://doi.org/10.1007/s11205-010-9589-4 
in the

EU [Çevrim-içi:

https://ec.europa.eu/eurostat/statistics-explained/index.php?title=Subjective_wellbeing_-_statistics\#Overall_life_satisfaction_in_the_EU_], Erişim tarihi: 12.10.2021.

Ercan, İ., Ediz, B. ve Kan, İ. (2004). Sağlık kurumlarında teknik olmayan boyut için hizmet memnuniyetini ölçebilmek amacıyla geliştirilen ölçek. Uludă̆ Üniversitesi Tıp Fakültesi Dergisi, 30(3), 151-157.

Erikson, E. H. ve Erikson, J. M. (1998). The life cycle completed. WW Norton \& Company.

Erol, M. ve Yıldırım, İ. (2016). Yükseköğrenim yaşam doyumu ölçeğinin geliştirilmesi. Eğitimde Kuram ve Uygulama, 12(1), 221-243.

Eygü, H. ve Karaman, S. (2013). Uzaktan eğitim öğrencilerinin memnuniyet algıları üzerine bir araştırma. Kırıkkale Üniversitesi Sosyal Bilimler Dergisi, 3(1), 36-59.

Eygü, H. ve Kılınç, A. (2020). Yaşam memnuniyeti üzerinde etkili olan faktörlerin araştırılması: Kayseri ili örneği. OPUS Uluslararası Toplum Araştırmaları Dergisi. 16(29), 3591-3618. https://doi.org/10.26466/opus.791217

Field, A. (2017). Discovering statistics using IBM SPSS statistics. Sage.

Gefen, D., Straub, D. W. ve Boudreau, M. (2000). Structural equation modeling and regression: Guidelines for research practice. Communications of The Association for Information Systems, 4(7), 1-78.

Genç, A. ve Karaman, F. (2019). Üniversite öğrencilerinde sağl1klı yaşam becerileri ölçeğinin $\quad$ geliştirilmesi. $\quad I G U S A B D E R, \quad 7, \quad 656-669$. https://doi.org/10.38079/igusabder.496557

Güllüpınar, F. (2017). Kamusallığın çöküşü ve bireyin sorumlulaştırılması olarak yaşam boyu öğrenme: Eğitim ve istihdam politikalarının eleştirisine bir katkı. Amme İdaresi Dergisi, 50(1), 67-84.

Güven, S. ve Şener, A. (2010). Factors affecting life satisfaction in old age. Turkish Journal of Geriatrics, 14(2), 179-186.

Hofstede, G., Hofstede, G. J. ve Minkov, M. (2010). Cultures and organizations: Software of the mind: Intercultural cooperationand its importance for survival. McGrw-Hill.

Huebner, E. S. (1991). Initial development of the students' life satisfaction scale. School Psychology International, 12, 231-240. 
M.F., Köse, G, Çobanoğlu ve R.Mercan Sarı/ Pamukkale Üniversitesi Eğitim Fakültesi Dergisi, 55, 324-346, 2022343

Kaba, İ., Erol, M. ve Güç, K. (2018). Yetişkin yaşam doyumu ölçeğinin geliştirilmesi. Anadolu Üniversitesi Sosyal Bilimler Dergisi, 18(1), 1-14. https://doi.org/10.18037/ausbd.550232

Karagöz, Y., Doğan, A. ve Koçyiğit, S. (2016). Gelir düzeyinin hayat kalitesi ve memnuniyetine etkisi: Sivas ilinde ampirik bir uygulama. C. ̈̈. Íktisadi ve Ídari Bilimler Dergisi, 17(1), 168-186.

Kaya, Ö. (2011). Öğrenci yaşam doyum ölçeğinin Türkçeye uyarlanması: Geçerlik ve güvenirlik çalışmaları. KHO Bilim Dergisi, 21(2), 173-185.

Korkmaz, M., Germir, H. N., Yüce, A. S. ve Gürkan, A. (2015). Yaşam memnuniyeti üzerinde etkili olan sosyo-demografik bileșenler üzerine bir analiz. Uluslararası Hakemli Psikiyatri ve Psikoloji Araştırmaları Dergisi, 2(3), 78-111.

Korukoğlu, A. (2003). Üniversite öğrencilerinin eğitimden beklentileri Ege Üniversitesi İ.İ.B.F. örneği. Süleyman Demirel Üniversitesi İktisadi ve İdari Bilimler Fakültesi Dergisi, 8(1), 79-89.

Köker, S. (1991). Normal ve sorunlu ergenlerin yaşam doyumu düzeyinin karşılaştırılması. Yayımlanmamış yüksek lisans tezi, Ankara Üniversitesi, Ankara.

Lavallee, L.F., Hatch, P.M., Michalos, A.C. ve McKinley, T. (2007). Development of the contentment with life assessment scale (CLAS): Using daily life experiences to verify levels of self-reported life satisfaction. Social Indicators Research, 83(2), 201244. https://doi.org/10.1007/s11205-006-9054-6.

Lightsey Jr, O. R., McGhee, R., Ervin, A., Gharghani, G. G., Rarey, E. B., Daigle, R. P., et al. (2013). Self-efficacy for affect regulation as a predictor of future life satisfaction and moderator of the negative affect-life satisfaction relationship. Journal of Happiness Studies, 14(1), 1-18.

Lyubomirsky, S., King, L., Diener, E. (2005). The benefits of frequent positive affect: does happiness lead to success?. Psychological Bulletin, 131(6), 803-855.

Maddux, J. E. (2018). Subjective well-being and life satisfaction: An introduction to conceptions, theories, and measures. In J. E. Maddux (Eds.), Subjective well-being and life satisfaction (pp. 3-31). Routledge/Taylor \& Francis Group.

Mannell, R.C., Dupuis, S. (2007). Life satisfaction. In J. E. Birren (Ed), Encyclopedia of Gerontology (pp. 73-79). Elsevier Print. 
McCamish-Svensson, C., Samuelsson, G., Hagberg, B., Svensson, T., Dehlin, O. (1999). Social relationships and health as predictors of life satisfaction in advanced old age: Results from a Swedish longitudinal study. The International Journal of Aging and Human Development, 48(4):301-324.

Mcdonald, R. P. ve Ho, R. H. (2002). Principles and practice in reporting structural equation analyses. Psychological Methods, 7, 64-82.

Mowrer, R. ve Parker, K. (2004). Revised multicultural perspective index and measures of depression, life satisfaction, shyness, and self-esteem. Psychological Reports, 95, $1227-1228$.

Myers, D. G. (2000). The funds, friends, and faith of happy people. American Psychologist, $55,56-67$.

Neugarten, B. L., Havighurst, R. J. ve Tobin, S. (1961). The measurement of life satisfaction, Journal of $\quad$ Gerontology, $\quad 16(2), \quad 134-143$. https://doi.org/10.1093/geronj/16.2.134.

OECD. (2021). OECD better life index life satisfaction [Çevrim-içi: https://www.oecdbetterlifeindex.org/topics/life-satisfaction/], Erişim tarihi: 12.10.2021.

Özberk Ünsal, E. B. (2017). Adalet Bakanlığı ceza infaz kurumları personeli eğitim merkezlerinde kullanılmak üzere bir ölçek geliştirme çalışması: Eğitim Memnuniyeti Ölçeği. İnönü Üniversitesi Eğitim Fakültesi Dergisi, 18(1), 70-82.

Özdamar, K. (2016). Ölçek ve test geliştirme yapısal eşitlik modellemesi. Eskişehir: Nisan Kitabevi.

Paolini, L., Yanez, A. P. ve Kelly, W. E. (2006). An examination of worry and life satisfaction among college students. Individual Differences Research, 4(5), 331-339.

Pavot, W., Diener, E. ve Suh, E. (1998). The temporal satisfaction with life scale. Journal of Personality Assessment, 70, 340-354.

Ramachandran, R. ve Radhika, R. (2012). SocioEconomic statüs, life satisfaction culturel perspective: The elderly Japon and India. International Journal of Humanities and Social Sicence, 2(16): 285-292. 
M.F., Köse, G, Çobanoğlu ve R.Mercan Sarı/ Pamukkale Üniversitesi Eğitim Fakültesi Dergisi, 55, 324-346, 2022345

Rojas, M. (2006). Life satisfaction and satisfaction in domains of life: Is it a simple or a simplified relationship?. Journal of Happiness Studies, 7(4), 467-497. https://doi.org/10.1007/s10902-006-9009-2

Schyns, P. (2002). Wealth of nations individual income and life satisfaction in 42 countries: A multilevel approach. Social Indicators Research, 60, 5-60.

Sousa, L. ve Lyubomirsky, S. (2001). Life satisfaction. In J. Worell (Eds.), Encylopedia of women and gender: sex similarities and differences and the impact of society on gender (Cilt:2, pp. 667-676). Academic Press.

Şahin, A. E. (2009). Eğitim fakültesinde hizmet kalitesinin Eğitim Fakültesi Öğrenci Memnuniyet Ölçeği (EF-ÖMÖ) ile değerlendirilmesi. Hacettepe Üniversitesi Ĕ̆itim Fakültesi Dergisi, 37 (37), 106-122.

Şahin, E., Göral, M., Demirel, M., Demirel, D. H. ve Arslan, F. (2014). Spor bilimleri fakültelerinde öğrenim gören öğrencilerin eğitim hizmetlerine ilişkin doyum düzeylerinin belirlenmesi. Turkish Journal of Education, 3(2) , 38-45. https://doi.org/10.19128/turje.181080

Şeker, M. (2011). İstanbul'da yaşam kalitesi araştırmast. İstanbul: İstanbul Ticaret Odası Yayınları, İstanbul'a Yönelik Araştırmalar, 2010-103.

Tabachnick, B. G., ve Fidell, L. S. (2007). Using multivariate statistics. Pearson.

Taşdelen-Karçkay, A. (2016). Family life satisfaction scale - Turkish version: Psychometric evaluation. Social Behavior and Personality, 44(4), 631-640. https://doi.org/10.2224/sbp.2016.44.4.631

Tezer, E. (1996). Evlilik ilişkisinden sağlanan doyum: Evlilik Yaşamı Ölçeği. Psikolojik Danışma ve Rehberlik Dergisi, 2(7),1-7.

Tinsley, H. E., ve Tinsley, D. J. (1987). Uses of factor analysis in counseling psychology research. Journal of Counseling Psychology, 34(4), 414-424.

Tuzgöl-Dost, M. (2005). Öznel İyi Oluş Ölçeği'nin geliştirilmesi: Geçerlik ve güvenirlik çalışması. Türk Psikolojik Danışma ve Rehberlik Dergisi, 3(23), 103-111.

TÜİK. (2021). Yaşam memnuniyeti araştırması, 2020, Haber bülteni, No: 37209. [Çevrimiçi: https://data.tuik.gov.tr/Bulten/Index?p=Life-Satisfaction-Survey-2020-37209], Erişim tarihi: 15.09.21). 
Ünal, L. I. (2013). Kapitalist toplumda eğitim: Kuram ve gerçekliğe genel bir bakış. Praksis, 33 (3), 9-27.

Ünsal, P. ve Özalp Türetgen, İ. (2005). Bir iş doyumu ölçeği geliştirme çalışması. Yönetim, 16(51), 43-55.

Vanderweele, T. J. (2017). On the promotion of human flourishing. PNAS, 114(31), 81488156. https://doi.org/10.1073/pnas.1702996114

Veenhoven, R. (1996a). The study of life satisfaction. In Saris, W.E., Veenhoven, R., Scherpenzeel, A.C. \& Bunting B. (Eds), A comparative study of satisfaction with life in Europe. Eötvös University Press.

Veenhoven, R. (1996b). Developments in satisfaction-research. Social Indicators Research, 37, 1-46.

Watson, D., Clark, L. A. ve Tellegen, A. (1988). Development and validation of brief measures of positive and negative affect: The PANAS scales. Journal of Personality and Social Psychology, 54, 1063-1070.

Yetim, B. ve Çelik, Y. (2020). Türkiye'de yaşam kalitesini ne öngörüyor: Ülkeyi temsil eden bir çalışmanın sonuçları. Toplumda Sağlık ve Sosyal Bakım, 28(2), 431-438.

Yetim, Ü. (1993). Kişisel projelerin organizasyonu ve örüntüsü açısından yaşam doyumu. Yayınlanmamış Doktora Tezi, Ege Üniversitesi, İzmir.

Zabriskie, R. B. ve Ward, P. J. (2014). Satisfaction with family life scale. Marriage \& Family Review 49(5), 446-463. https://doi.org/10.1080/01494929.2013.768321 
The Life Satisfaction Scale and its Psychometric Properties

\author{
Mehmet Fatih KÖSE $^{*}$ Gözde ÇOBANOĞLU** $\quad$ Rahime MERCAN SARI***
}

- Received: 06.11.2021 • Accepted: 04.02.2022 • Online First: 04.02.2022

\begin{abstract}
The present study aims to develop a valid, reliable metric that assesses general life satisfaction based on basic life domains. The study group consists of 1,533 randomly selected young people studying in high school and university. We conducted an exploratory (EFA) and confirmatory factor analysis (CFA) to determine the scale's structural properties. The EFA results reveal that life satisfaction can be evaluated in two subdimensions (i.e., economic life satisfaction and personal/social life satisfaction). The CFA confirmed that this scale is composed of two factors and that it featured an acceptable fit for use with both university and high school students. After assessing criterion validity and discriminatory validity, we found that the scale was valid in these two criteria. Reliability coefficients exceeded the acceptable threshold of .70 for the entire scale and its subdimensions. After the study, we found that satisfaction with economic life explains $51 \%$ of the total variance, whereas satisfaction with personal/social life explains only 13\%. There is strong evidence that the scale developed during this study (i.e., the Life Satisfaction Scale) is a valid, reliable metric. Accordingly, we recommend that the Life Satisfaction Scale be used by researchers and practitioners alike to evaluate general life satisfaction based on how the same person perceives his satisfaction levels in basic life domains.
\end{abstract}

Keywords: life domains, life satisfaction, well-being, economic life, personal/social life.

\title{
Cited
}

Köse, M.F., Çobanoğlu, G., \& Mercan Sarı, R.(2022). The life satisfaction scale and its psychometric properties. Pamukkale University Journal of Education, 55, 324346.doi:10.9779.pauefd.1020012

\footnotetext{
* PhD, MoYS, General Directorate of Education, Research, and Coordination ORCID: 0000-0002-2297-8152, m.fatihkose@gmail.com

** PHD Candidate, Hacettepe University Department of Statistics, ORCID: 0000-0001-6816-9329, gozde.cobanoglu@gsb.gov.tr

*** PHD Candidate, Hacettepe University Department of Sociology, ORCID: 0000-0003-0262-8478, Rahime.SARI@gsb.gov.tr
} 


\section{Introduction}

Individuals' general life satisfaction and satisfaction with specific domains of their lives are, in addition to personal happiness, closely related to interpersonal relationships and general social well-being. Since policymakers regard individual happiness to be fundamental in improving social well-being, they pay close attention to assessments made on life satisfaction while making decisions seeking to increase social well-being and life satisfaction. As such, international institutions, such as the Organisation for Co-operation and Development (OECD) and the European Commission (EC), have assessed life satisfaction for many years (EC, 2019; OECD, 2021). Similarly, the Turkish Statistical Institute (Türkiye İstatistik Kurumu and, henceforth, TÜİK) has, since 2003, regularly released a report on how individuals perceive their happiness levels, what factors impact satisfaction levels, and how satisfaction levels have changed over time (TÜIK, 2021).

In most general terms, life satisfaction means either accepting or being content with one's circumstances (Sousa \& Lyubomirsky, 2001). The social sciences have given the great interest in what causes one to be satisfied with his/her own life and what effects being satisfied has on said individual's life. Accordingly, the literature is rife with studies focusing on what factors have an impact on life satisfaction (Ar1 \& Y1ld1z, 2016; Çebi Karaaslan, Çalmaşur, \& Emre Aysin, 2021; Eygü \& Kılınç, 2020; Güven \& Şener, 2010; Ramachandiran \& Radhika, 2012). These studies have demonstrated, among others, gender, age, marital status, educational status, health, family relations, love, and compassion all to have and impact on life satisfaction (Akdeniz, Aydemir, Akdeniz, Gülseren, \& Kültür, 1999; Karagöz, Doğan, \& Koçyiğit, 2016; Korkmaz, Germir, Mannell, \& Dupuis, 2007; Şeker 2011; Yetim \& Çelik, 2020; Yücel \& Gürkan, 2015). In addition to studies examining which factors inform life satisfaction, studies seeking to determine the effects of life satisfaction on an individual's life comprise a significant portion of the literature on this subject (Lyubomirsky, King \& Diener, 2005; Schyns, 2002). Lyubomirsky et al. (2005, p. 828) found that individuals highly satisfied with their lives are generally more social, altruistic, and active, have stronger bodies and immune systems, and have more effective problemsolving skills. Similarly, Beșel (2015) found that areas with high life satisfaction boast lower unemployment, divorce, electrical use, and population density compared to areas with low life satisfaction levels. Given the importance that life satisfaction has for both the individual and society, it has come to attract the attention of numerous researchers from different disciplines. 


\section{Life Satisfaction and Related Concepts}

Life satisfaction is defined as a part of the larger field of research on the quality of life that seeks to determine what the criteria for a good life are, to what degree these criteria conform with real life, and what needs to be done to attain these criteria (Veenhoven, 1996a, p. 11). Life satisfaction means to accept or be content with one's life circumstances; it means for one to sate all of his wants and needs. In other words, it means to perform a comprehensive and objective evaluation of one's quality of life (Sousa \& Lyubomirsky, 2001, p. 668). Regarding the difference between one's expectations and possessions, Neugarten, Havighurst, and Tobin (1961) were the first to coin the term life satisfaction. Life satisfaction is furthermore considered a part of subjective well-being. Whereas subjective well-being is tied to how one cognitively and affectively assesses his/her own life and the inferences s/he makes, as a result, subjective life satisfaction prioritizes the cognitive aspect of subjective well-being (Diener, 1984). Studying subjective well-being and developing scales on life satisfaction, Diener, Emmons, Larsen, and Griffen (1985) define life satisfaction as a method to evaluate every dimension of one's life. Duckworth, Seligman, and Steen (2005, p. 636) define the components of subjective well-being as the existence of positive affect, the absence of negative affect, cognitive satisfaction, and life-satisfaction judgments. Myers (2000, p. 60) and Maddux (2018, p. 3-4) emphasize that in studies on subjective well-being, it is generally necessary to distinguish between the objective circumstances of a person's life, his/her subjective evaluation of his/her life, and his/her emotions. Knowing this, one's quality of life is assessed both objectively and subjectively: whereas the degree to which an individual's observable criteria respond to his/her life circumstances is assessed objectively, one's subjective quality of life is, rather naturally, assessed subjectively (Veenhoven, 1996b, p. 1). Since life satisfaction is contained subjective assessments about one's own life, this concept is defined as the holistic and cognitive-judgmental evaluation of a person's life (Diener et al., 1985).

The literature distinguishes between life domain satisfaction and life satisfaction. The former refers to the feeling of content one has toward his/her work, marriage, and income, while general life satisfaction refers to the opinions, one has reached concerning his/her life and is, as a result, more comprehensive than life domain satisfaction (Rojas, 2006; Sousa \& Lyubomirsky, 2001, p. 668). Life domains include various aspects of one's private life whose boundaries are defined by the individual and the dominant culture. The impact that different domains have on one's general life satisfaction are frequently addressed in studies 
M.F, Köse, G. Çobanoğlu, \& R.Mercan Sarı / Pamukkale Üniversite Journal of Education, 55, 324-346, 2022

dealing with the subject Barraca, Yarto, \& Olea, 2000; Cummins, 1996, 1998, 2003; Dal \& Sevuktekin, 2018; McCamish-Svensson, Samuelsson, Hagberg, Svensson, Dehlin, 1999; Rojas, 2006; Veenhoven, 1996a; Zabriskie \& Ward, 2013). Though the domains that are afforded importance and that are considered to produce happiness differ in each culture, it is not impossible to determine a standard conception (Hofstede, Hofstede, \& Minkov, 1991, p. 279). Cummins (1996), for instance, performed a meta-analysis on different life domains and the impact they have on life satisfaction. His analyses found that life satisfaction can be measured along with material well-being, health, productivity, intimacy, security, emotional well-being, and community.

\section{Assessing Life Satisfaction}

Various scales have been developed in the literature assessing individuals' life satisfaction levels, what factors determine one's satisfaction level, and what factors are affected by life satisfaction. Diner et al. (1985) developed the first of such scales (Satisfaction with Life Scale). This scale was subsequently found to be valid and reliable for use with different groups (Diener, Pavot, Colvin \& Sandvik, 1991; Diener \& Pavot, 1993). Following this pioneering work, several other scales were developed to assess life satisfaction in groups manifesting a variety of different characteristics (Andrews \& Withey, 1976; Lavallee, Hatch, Michalos, \& McKinley, 2007; Lightsey Jr, McGhee, Ervin, Gharghani, Rarey, Daigle, Wright, Powell, 2013; Mowrer \& Parker, 2004; Paolini, Yanez, \& Kelly, 2006; Pavot, Diener, \& Suh, 1998; Watson, Clark, \& Tellegen, 1988). Several scales, including those developed by Diener et al. (1985), Lavallee et al. (2007), and Huebner (1991), have been adapted to Turkish and subsequently used on different population groups in Turkey (Akandere, Acar, \& Baştuğ, 2009; Akın \& Yalnız, 2015; Altay \& Ekşi,2018; Çivitçi, 2007; Dağlı \& Baysal, 2016; Durak, Şenol-Durak, \& Gençöz, 2010; Erol \& Y1ldırım, 2016; Kaba, Erol, \& Güç, 2018; Kaya, 2011; Köker, 1991; Yetim, 1993). In addition to these adapted scales are other original scales developed specifically for a Turkish context (Özberk Ünsal, 2017; Tuzgöl-Dost, 2005; Ünsal \& Özalp Türetgen, 2005). Whether adapted to Turkish or original works themselves, these scales contain questions allowing researchers of different fields to delve into field-specific details. Whereas, for instance, a scale used in the field of education may include questions about curricula and the physical conditions of schools (Özberk Ünsal, 2017), a scale used in the health field may focus on patient relations and/or the physical conditions of hospitals (Ercan, Ediz, \& Kan, 2004). 
Şeker (2011) evaluated life satisfaction according to six life domains (i.e., health, family life, security, education, and social life). Previous studies have focused on healthy living skills and health satisfaction (Akdeniz et al., 1999; Genç \& Karaman, 2019), marriage satisfaction (Tezer, 1996), satisfaction with family life (Taşdelen-Karçkay, 2016), satisfaction with education (Şahin, 2009; Eygü \& Karaman, 2013; Şahin, Göral, Demirel, Demirel, \& Arslan, 2014), and satisfaction with work-life (Çevik \& Korkmaz, 2014). Some of these studies developed scales or adapted extant scales to a novel population. A cursory assessment of the literature reveals life satisfaction to be a cultural phenomenon whose dynamics differ depending on the context, individual, and society - all of these need to be taken into account in any endeavor to measure satisfaction.

A survey of the literature considering the above notions reveals that studies on life satisfaction focus on individuals of different ages and profiles or satisfaction in a specific domain. We likewise see that several scales have been created as a result. The relevant indicate a strong correlation between satisfaction in life domains and general life satisfaction (Dal \& Sevüktekin, 2018). The literature also investigates the effect of life domains on life satisfaction (Dal \& Sevüktekin, 2018; Rojas, 2006). Yet, although satisfaction in different life domains is frequently asked about in statistical research (OECD, 2021; TÜIK, 2021), there exists no scale focusing on this particular phenomenon. Accordingly, the current study differs from previous studies in the literature in that we have sought to develop a scale that itself seeks to ascertain an individual's general life satisfaction by determining how satisfied said individual is indifferent life domains (i.e., family life, social life, economic life, spiritual life, health, educational life, and work-life). According to Rojas (2006), one must understand the nature of the relationship between satisfaction in specific life domains and general life satisfaction and how changes in satisfaction in one domain affect other domains. As such, we anticipate that assessing one's satisfaction will assist policymakers, researchers, and other stakeholders in determining what causes an individual to be either satisfied or dissatisfied with his/her life and what practical interventions may be viable. Life satisfaction emerges through the interplay and/or due to several factors related to an individual's social and personal life. Given this, the ability to assess life satisfaction in a cogent manner will aid researchers to pinpoint just how family, school, and work-life interact with a person's life in general. The current study aims to develop a scale capable of evaluating life satisfaction in light of different life domains. 


\section{Method}

\section{Study group}

For this study, we used simple random sampling to reach 1,533 high school and university students living in twelve different regions as defined by the Nomenclature of Territorial Units for Statistics (NUTS 1). Whereas according to Erikson's psychosocial development theory, adolescence (12-18 years) is defined as a conflict between identity and role confusion, young adulthood (19-40 years) is defined by a conflict between intimacy and isolation (Erikson \& Erikson, 1998). With this in mind, in addition to evaluating their psychometric properties, we assessed the validity and reliability of the scales separately for each participant group whilst taking into account the differences in knowledge, skills, perceptions, attitudes, and values expected during these two periods of psychosocial development. We, therefore, conducted all analyses separately for the groups of high school and university students in question and reported the results that we obtained. Table 1 shows participants' demographics.

Table 1. Study Group Demographics

\section{Groups}

Demographics

\begin{tabular}{llll} 
Group 1 & & \multicolumn{3}{c}{ Group 2 } \\
\hline $\mathrm{n}$ & $\%$ & $\mathrm{n}$ & $\%$
\end{tabular}

Gender

Male 245

49.2 566

Female

253

50.8

469

45.3

Education

\begin{tabular}{lcccc} 
High School & 226 & 45.4 & 403 & 39.0 \\
Vocational Degree & 116 & 23.3 & 253 & 24.4 \\
Bachelor's Degree or Higher & 156 & 31.3 & 379 & 36.6 \\
\hline Total & 498 & 100 & 1035 & 100
\end{tabular}

Tinsley and Tinsley (1987) state that while developing a scale, the study group should be at least five to ten times greater larger than the number of items included in the 
scale. Accordingly, we deemed two separate groups (one composed of high school and university students) to form a sufficiently large study group.

\section{Process and Data Analysis}

During the first segment of the study, we performed a survey of the literature and consulted with field experts to develop a pool made up of fifty items based on theories on life domains. DeVellis (2012) states that an initial item pool should be four to five times larger than the final version of the form. A twelve-member focus group comprised education scientists, sociologists, psychologists, and educational assessment specialists who worked on the item pool. Özdamar (2016) maintains that scales dealing with phenomena lacking a theoretically complex structure need not contain a high number of items. The resulting fivepoint Likert scale (Completely Disagree=1, Completely Agree=5) was executed to a total of 1,533 high school and university students in two stages (498 for the first and 1,035 for the second stage). We conducted an Exploratory Factor Analysis (EFA) to examine the scale's structural properties during the first stage. The EFA revealed three items with a factor loading near .10 $(\mathrm{x}<.10)$. We consulted field experts once against, which resulted in our removal of two items and the third remaining in the scale after being revised. After these revisions, we moved on to the second stage of collecting data, rechecked the scale's structural properties, and came up with the Life Satisfaction Scale.

Because of the ongoing COVID-19 pandemic, data were collected online. We used both SPSS 26 and AMOS 26 to analyze data. Before conducting analyses, we examined lost and missing data. We excluded any outliers whose z-scores were outside the \pm 2 range from analyses. Based on this, both the univariate and multivariate normality assumptions were met for the data set (Tabachnick \& Fidell, 2007). We examined the observed differences between scatter plots to test the linearity assumption for the data set. We concluded that linearity and normality assumptions were mot. Based on this, we conducted separate EFAs to test the scale's structural features, which we confirmed with a CFA. We ran Bartlett's and Kaiser-Meyer-Olkin (KMO) Tests to ascertain whether data were suitable for factor analysis. While performing the EFA, we opted to rotate the factors obliquely when the correlation between factors was greater than .32 (Tabachnick \& Fidell, 2007). We then used the eigenvalue to identify the number of important factors, considering a value greater than 1 to indicate importance (Büyüköztürk, 2007). After this, we performed a CFA to test the new model's fit indices $\left[x^{2} / \mathrm{sd} .<5, \mathrm{NFI}>.90, \mathrm{CFI}>.90, \mathrm{RMSEA}<.08, \mathrm{GFI}>.80\right]$ (Gefen, Straub, \& Boudreau, 2000; McDonald \& Ho, 2002). We calculated the correlation values between 
subdimensions and Cronbach's alpha $(\alpha)$ to ascertain scale reliability. We used a similar scale with similar parameters found in the literature to test our scale's criteria validity. After all this, we found our single-factor, five-item scale to have excellent model fit $\left[\chi^{2} / \mathrm{sd}=1.17\right.$; RMSEA=.03; GFI=.99; CFI=1.00; NFI=.99]. We likewise found an internal consistency value of .88 (Dağlı \& Baysal, 2016). We also found an internal consistency value of .84 for the Satisfaction with Life Satisfaction Scale. Finally, we conducted a $t$-test to determine the difference between the upper and lower twenty-seventh percentile groups.

\section{Findings}

During the first stage of the study, we performed two separate EFAs on the data collected from high school and university students of the first study group. The results revealed three items whose factor loadings were close to .10. After consulting field experts, we decided to remove two of these items and leave the third item on the scale after revising it. The eightitem scale was distributed to 1,035 participants (403 high school and 632 university students). The scale's structural characteristics were evaluated based on the results. Based on this, the KMO values were .877 for university studies were and .881 for high school students. Bartlett's test was significant $(\mathrm{p}<.001)$ for both groups. Consequently, we performed an EFA to ascertain the scale's factorial structure and components to explain the total variance. Table 2 shares the EFA results and the revised item correlation coefficients.

The EFA results revealed that the Life Satisfaction Scale is composed of two factors for both high school and university students and explains $66.57 \%$ of total variance for high school students and $66.17 \%$ for university students. The first (items $2,3,4,5$ ) and second factor $(1,6,7,8)$ contained four items. In contrast, an individual's health, family life, social life, and spiritual life are aggregated under one factor, economic life, educational life, worklife, and life standards aggregated under the other. After examining items' theoretical properties and soliciting expert opinion, we decided to name the first-factor satisfaction with personal/social life and the second satisfaction with economic life. The lowest item-total correlation was .537 , and scores of 3.0 or greater indicate a strong correlation 


$\begin{array}{ccc}\text { Components } & \begin{array}{c}\text { Corrected Item } \\ \text { Correlation } \\ \text { Coefficients }\end{array}\end{array}$

1. I'm satisfied with my economic status. $.889(.934)$

2. I'm satisfied with my family life. $\quad .815(.768)$

3. I'm satisfied with my health. $\quad .907(.894) \quad .552(.578)$

4. I'm satisfied with my social life. $\quad .584(.502) \quad .627(.663)$

5. I'm satisfied with my spiritual life (religious, spiritual, etc.).

6. I'm satisfied with my life standards. $\quad .894(.865)$

7. I'm satisfied with my education level. $\quad .743(.832)$

8. I'm satisfied with my job. $\quad .768(.632)$

$\begin{array}{lll}\text { Eigenvalue } & 4.20(4.16) & 1.10 \\ & & (1.17) \\ \text { Variance explained }(\%) & 52.45 & 13.72 \\ & (51.99) & (14.58)\end{array}$

Total variance explained $(\%) \quad 66.17(66.57)$

Note: Values inside parentheses belong to high school students.

The EFA results revealed that the Life Satisfaction Scale is composed of two factors for both high school and university students and explains $66.57 \%$ of total variance for high school students and $66.17 \%$ for university students. The first (items 2, 3, 4, 5) and second factor $(1,6,7,8)$ contained four items. In contrast, an individual's health, family life, social life, and spiritual life are aggregated under one factor, economic life, educational life, worklife, and life standards aggregated under the other. After examining items' theoretical properties and soliciting expert opinion, we decided to name the first-factor satisfaction with 

personal/social life and the second satisfaction with economic life. The lowest item-total correlation was .537 , and scores of 3.0 or greater indicate a strong correlation

In line with the EFA results, we then used AMOS to conduct a CFA to confirm the scale's factorial structure for both groups. Figure 1 provides the results of the CFA.

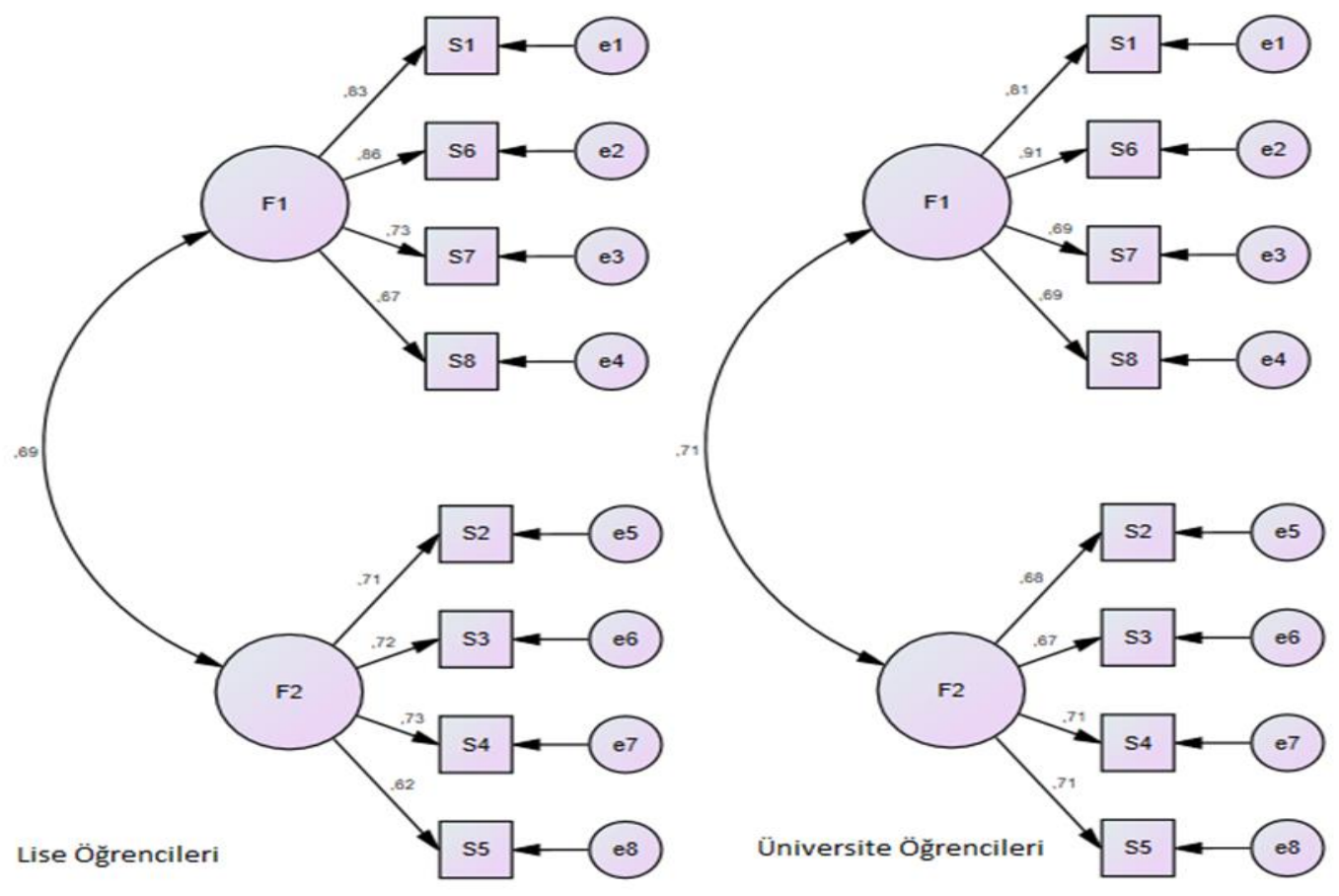

Figure 1. CFA Results for the Theoretical Model

Figure 1 shows that, based on the CFA results for high school $\left[x^{2} / \mathrm{sd}=3,62\right.$; RMSEA=.080; GFI=.958; CFI=.964; NFI=.951] and university students $\left[x^{2} / \mathrm{sd}=4.93\right.$; RMSEA=.079; GFI=.962; $\mathrm{CFI}=.966 ; \mathrm{NFI}=.958]$, the two-factor structure is an acceptable model fit for both groups.

Table 3 shows the internal consistency and factor correlation values for the twofactor structure. 


\begin{tabular}{lcccccc}
\hline & $\overline{\boldsymbol{x}}$ & SS & A & $\mathbf{1}$ & $\mathbf{2}$ \\
\hline 1. Entire Scale & 2.29 & $.97(1.06)$ & $.86(.86)$ & 1 & \\
& $(2.50)$ & & & & \\
2. Satisfaction with Personal/Social Life & 1.73 & $.96(1.10)$ & $.85(.84)$ & $.87^{*}$ & 1 \\
& $(1.94)$ & & & $\left(.87^{*}\right)$ & \\
3. Satisfaction with Economic Life & 2.85 & 1.21 & & $.92^{*}$ & $.69^{*}$ \\
& $(3.05)$ & $(1.28)$ & & $\left(.91^{*}\right)$ & $\left(.71^{*}\right)$ \\
\hline
\end{tabular}

$* \mathrm{p}<.001 \quad * *$ Values inside parentheses belong to high school students.

Table 3 shows that Cronbach's alpha coefficient $(\alpha)$ for the factors is acceptable .75 (Özdamar, 2016). The inter-factor correlation value was .71 for high school students and .69 for university students.

Though the correlation between factors was statistically significant, our analyses revealed the existence of multicollinearity (Büyüköztürk, 2007). A correlation greater than .90 indicates that two variables may perform the same operation, meaning that one or more variables may very well be unnecessary (Tabachnick \& Fidell, 2007). Given this, we investigated the correlation between the variables making up the scale's items in greater detail to check for singularity and multicollinearity issues between variables. Table 4 presents the correlation results.

Looking at interitem correlations, the most highly correlated variables were life standards and economic status (.736). However, the least correlated were health and economic life (.288). Since no correlation coefficient was greater than .90, we found no multicollinearity issues. We found a positive linear correlation between all life domains, indicating satisfaction with all life domains tended to converge on each other. Generally speaking, this means that a person's satisfaction with certain life domains tended to change positively or negatively together. 


\begin{tabular}{|c|c|c|c|c|c|c|c|c|c|}
\hline & $\bar{x}$ & SS & 1 & 2 & 3 & 4 & 5 & 6 & 7 \\
\hline $\begin{array}{l}\text { 1. Economic } \\
\text { Status }\end{array}$ & $\begin{array}{c}1.54 \\
(1.77)\end{array}$ & $\begin{array}{c}1.02 \\
(1.23)\end{array}$ & 1 & & & & & & \\
\hline $\begin{array}{l}\text { 2. Family } \\
\text { Life }\end{array}$ & $\begin{array}{c}2.98 \\
(3.14)\end{array}$ & $\begin{array}{c}1.59 \\
(1.68)\end{array}$ & $.353 *$ & 1 & & & & & \\
\hline 3. Health & $\begin{array}{c}3.48 \\
(3.48)\end{array}$ & $\begin{array}{c}1.58 \\
(1.61)\end{array}$ & $.288 *$ & $.530 *$ & 1 & & & & \\
\hline 4. Social Life & $\begin{array}{c}2.31 \\
(2.56)\end{array}$ & $\begin{array}{c}1.45 \\
(1.56)\end{array}$ & $.453 *$ & $.465 *$ & $.500 *$ & 1 & & & \\
\hline $\begin{array}{l}\text { 5.Spiritual } \\
\text { Life }\end{array}$ & $\begin{array}{c}2.64 \\
(3.02)\end{array}$ & $\begin{array}{c}1.56 \\
(1.69)\end{array}$ & $.359 *$ & $.482 *$ & $.479 *$ & $.448^{*}$ & 1 & & \\
\hline $\begin{array}{l}\text { 6.Life } \\
\text { Standards }\end{array}$ & $\begin{array}{c}1.69 \\
(1.92)\end{array}$ & $\begin{array}{c}1.11 \\
(1.29)\end{array}$ & $.736 *$ & $.385^{*}$ & $.349 *$ & $.536^{*}$ & $.428 *$ & 1 & \\
\hline 7. Education & $\begin{array}{c}1.75 \\
(1.78)\end{array}$ & $\begin{array}{c}1.16 \\
(1.25)\end{array}$ & $.578 *$ & $.378^{*}$ & $.305^{*}$ & $.429 *$ & $.401 *$ & $.616^{*}$ & 1 \\
\hline 8. Work Life & $\begin{array}{c}1.94 \\
(2.30)\end{array}$ & $\begin{array}{c}1.33 \\
(1.56)\end{array}$ & $.545^{*}$ & $.368 *$ & $.336^{*}$ & $.432 *$ & $.409 *$ & $.595^{*}$ & $.493 *$ \\
\hline$* \mathrm{p}<.001$ & lues & pare & ses & ng & gh s & ol st & ents. & & \\
\hline
\end{tabular}




\begin{tabular}{lccc}
\hline & 1 & 2 & 3 \\
\hline 1. Life Satisfaction & 1 & .651 & .526 \\
2. Personal/Social Life & & 1 & .503 \\
3. Economic Life & & & 1
\end{tabular}

Criterion validity shows that two related models are theoretically correlated (DeVellis, 2012). Table 5 provides strong evidence for the existence of a positive, significant correlation between the subdimensions of the Life Satisfaction Scale and the Satisfaction with Life Scale.

Finally, we conducted a paired $t$-test to evaluate the difference between the upper and lower twenty-seventh percentile groups, as this will reveal the scale's discriminatory power. Table 6 presents the results of the said test.

Table 6. Difference between the Upper and Lower Twenty-Seventh Percentile Groups

\begin{tabular}{|c|c|c|c|c|c|}
\hline & Groups & $\overline{\boldsymbol{x}}$ & SS & $t$ & $\mathbf{p}$ \\
\hline \multirow{3}{*}{ Entire Scale } & Lower & 1.21 & .208 & \multirow{3}{*}{-66.20} & \multirow{3}{*}{.000} \\
\hline & & & & & \\
\hline & Upper & 3.70 & .594 & & \\
\hline \multirow{3}{*}{ Satisfaction with Personal/Social Life } & Lower & 1.38 & .407 & \multirow{3}{*}{-65.67} & \multirow{3}{*}{.000} \\
\hline & & & & & \\
\hline & Upper & 4.32 & .628 & & \\
\hline \multirow{3}{*}{ Satisfaction with Economic Life } & Lower & 1.03 & .120 & \multirow{3}{*}{-33.36} & \multirow{3}{*}{.000} \\
\hline & & & & & \\
\hline & Upper & 3.08 & 1.016 & & \\
\hline
\end{tabular}

Table 6 shows that the difference between the highest and lowest groups was statistically significant $\left(t_{\min }=-33.36 ; \mathrm{p}>.001\right)$. This, in turn, indicates that the scale has high discriminatory power for all factors and subfactors. 


\section{Scoring}

The scale was composed of two subdimensions and a total of eight items - none of which required being reverse scored. Whereas items 2, 3, 4, and 5 pertain to personal/social life satisfaction, items 1, 6, 7, and 8 pertained to satisfaction with economic life. Possible scores ranged between 8 and 40, with a high score indicating high life satisfaction. The participants' scores ranged between 8 and $40(\bar{x}=18.97, \mathrm{sd}=8.09)$ in our study.

\section{Discussion, Results, and Recommendations}

The current study has endeavored to develop a scale capable of evaluating an individual's general life satisfaction level by understanding how s/he perceives his/her own satisfaction levels in certain life domains. The studies conducted on the validity and reliability of the Satisfaction With Life Scale provide strong evidence that it is a valid and reliable metric that researchers and other stakeholders can use in their research and other ventures.

The theoretical and statistical analyses of the scale's factorial makeup reveal a twofactor model (satisfaction with personal/social life and satisfaction with economic life). The theoretical model demonstrates a statistically strong model fit. Internal consistency scores for both subfactors were found to be above acceptable limits. Whereas one's satisfaction with personal/social life expresses said, individual's satisfaction with his family and social relations, health, and spiritual life, satisfaction with economic life pertains to an individual's satisfaction with education, work, general economic status, and living standards. The findings likewise reveal a strong, statistically significant correlation between social/personal life satisfaction and satisfaction with economic life. Concerning the variance explained by the study's subcomponents, satisfaction with economic life can explain general life satisfaction at a rate of roughly four times higher than satisfaction with social life. This finding indicates that the economy has a strong, definitive impact on an individual's other life domains. Rojas's (2006) groundbreaking study on the nature of the relationship between satisfaction with life domains and general life satisfaction shows that some domains impact general life satisfaction. According to Vanderweele (2017), life constantly interacts with one's family, work, health, community, and spirituality. This compels individuals to strike a balance between these different aspects. Accordingly, future studies are recommended to focus on the relationship between how satisfied people from different socio-economic backgrounds are about economic life and how satisfied they are with their personal and social lives. 
Given that they are two fundamental elements of an individual's life, personal/social life and economic life were included in the scale's theoretical scope together with family, health, education, work, economy, and social life commonly found in the literature on life domains (Cummins, 1996; Dal \& Sevuktekin, 2018; Rojas, 2006; Sousa \& Lyubomirsky, 2001; Vanderweele, 2017). Considering that the boundaries between life domains fluctuate by culture (Hofstede et al., 1991), the study group composed of high school and university students used in our research had similar psychological dynamics concerning education, work, and economy. That the students considered education, given its many functions in an individual's personal, social, political, and economic life, to be an element of economic life is an important finding. When this is coupled with the finding that university students expect their education to guarantee a good job and income in the future (Korukoğlu, 2003), we may conclude that they have adopted a pragmatist understanding of education. In light of their criticisms toward a perceived capitalist education, this understanding harkens to notions that education, instead of being a means for young people to realize their potential as competent and free individuals, locks them into a fixed social status or position in the working world (Ünal, 2011) and, by shredding their communal bonds and desire to serve their community, restricting them to focusing on economic priorities (Güllüpınar, 2017). Based on the empirical data collected from high school and university students, we strongly recommend embracing a philosophy of education that prioritizes high-level values like socialization, being a service to one's community, and self-actualization instead of economic prerogatives while devising educational policies.

The General Satisfaction Scale is an alternative to current domain-specific satisfaction scales extant in the literature (Ercan, Ediz, \& Kan, 2004; Özberk Ünsal, 2017; Ünsal \& Özalp Türetgen, 2005). Based on our study, the Life Satisfaction Scale is a valid, reliable scale that researchers and practitioners can use to gauge individuals' general life satisfaction based on how satisfied they are in different life domains. Considering the small size of the sample group, this scale can be used with different socio-economic groups to flesh out any differences in its structural properties. Furthermore, since the ongoing COVID19 pandemic forced us to collect data online, we were unable to measure test-restest reliability. Therefore, future students can reexamine the scale's structural properties and be executed with different age and socio-economic groups. 
M.F, Köse, G. Çobanoğlu, \& R.Mercan Sarı / Pamukkale Üniversite Journal of Education, 55, 324-346, 2022

Ethical Approval: Ethical approval was obtained from the Scientific Research and Publication Ethics Committee of the Ministry of Youth and Sport with decision no 917650 dated 03.09.2021.

Conflict of interest disclosure: The authors declare no conflict of interest.

Author contributions: All authors contributed to the manuscript equally

\section{Reference}

Akandere, M., Acar, M., Baştuğ, G. (2009). Zihinsel ve fiziksel engelli çocuğa sahip anne ve babaların yaşam doyumu ve umutsuzluk düzeylerinin incelenmesi. Selçuk Üniversitesi Sosyal Bilimler Enstitüsü Dergisi, 22(1), 23-32.

Akdeniz, C., Aydemir, Ö., Akdeniz, F., Gülseren, Ş., Kültür, S. (1999). Sağlık Düzeyi Ölçeği’nin Türkçeye uyarlanması ve güvenilirliği. Klinik Psikofarmakoloji Bülteni, 9(2), 104-108.

Akın, A., Yalnız, A. (2015). The Satisfaction With Life Scale (YMÖ) Türkçe formu: Geçerlik ve güvenirlik çalışması. Elektronik Sosyal Bilimler Dergisi, 14(54), 95-102. https://doi.org/10.17755/esosder.68461

Altay, D., Ekşi, H. (2018). Çocuklar için yaşam doyum ölçeği geçerlilik güvenilirlik çalışması. 5. Uluslararası Ĕ̈itim Bilimleri Sempozyumu'nda sunulan tam metin bildiri (pp. 354-362), İstanbul, Türkiye.

Andrews, F.A., Withey, S.B. (1976). Social indicators of well being: Americans' perceptions of life quality. Plenum.

Arı, E., Yıldız, Z. (2016). Bireylerin yaşam memnuniyetini etkileyen faktörlerin sıralı lojistik regresyon analizi ile incelenmesi. Journal of International Social Research, 9(42):1362-1362.

Barraca, J., Yarto, L. L., Olea, J. (2000). Psychometric properties of a new family life satisfaction scale. European Journal of Psychological Assessment, 2, 98-106.

Beşel, F. (2015). 2013 yılı yaşam memnuniyeti araştırması sonuçlarının il bazlı ekonomik, sosyal ve siyasi analizi. Karabük Üniversitesi Sosyal Bilimler Enstitüsü Dergisi, 5(2), $227-236$

Büyüköztürk, Ş. (2007). Sosyal bilimler için veri analizi el kitabı. Pegem. 
340 M.F, Köse, G. Çobanoğlu, \& R.Mercan Sarı / Pamukkale Üniversite Journal of Education, 55, 324-346, 2022

Cummins, R.A. (1996). The domains of life satisfaction: An attempt to order chaos. Social Indicators Research, 38, 303-332.

Cummins, R.A. (1998). Directory of instruments to measure quality of life and cognate areas. Melbourne: School of Psychology, Deakin University.

Cummins, R.A. (2003). A model for the measurement of subjective well-being through domains. Melbourne: School of Psychology, Deakin University.

Çebi-Karaaslan, K., Çalmaşur, G., Emre-Aysin, M. (2021), Bireylerin yaşam memnuniyetlerini etkileyen faktörlerin incelenmesi. Atatürk Üniversitesi Íktisadi ve İdari Bilimler Dergisi, 35(1), 263-290. https://doi.org/10.16951/atauniiibd.789275

Çevik, N.K., Korkmaz, O. (2014). Türkiye'de yaşam doyumu ve iş doyumu arasındaki ilişkinin iki değişkenli sıralı probit model analizi. Niğde Üniversitesi İktisadi ve İdari Bilimler Fakültesi Dergisi, 7(1), 126-145.

Çivitci, A. (2007). Çok boyutlu öğrenci yaşam doyumu ölçeğinin Türkçeye uyarlanması: geçerlik ve güvenirlik çalışmaları. Eurasian Journal of Educational Research, 26, $51-60$.

Dağlı, A., Baysal, N. (2016). Yaşam doyumu ölçeğinin Türkçeye uyarlanması: geçerlik ve güvenirlik çalışması. Elektronik Sosyal Bilimler Dergisi, 15(59), 1250-1262. https://doi.org/10.17755/esosder.263229

Dal, S., Sevüktekin, M. (2018). Türkiye'de subjective well-being yaşam alanları yaklaşımı ile ölçülmesi. Uluslararası İktisadi ve İdari İncelemeler Dergisi, 18. EYİ Özel Sayısı, 433-446. https://doi.org/10.18092/ulikidince.351465

DeVellis, R.F. (2012). Scale development: Theory and applications. Sage.

Diener, E. (1984). Subjective well being. Psychological Bulletin, 95(3), 542-575.

Diener, E., Pavot, W.G. (1993). Review of the satisfaction with life scale. Psychological Assessment, 5, 164-172.

Diener, E., Emmons, A.R., Larsen, J. R., Griffin, S. (1985). The satisfaction with life scale. Journal of Personality Assessment, 49(1), 71-75.

Diener, E., Pavot, W.G., Colvin, C.R., Sandvik, E. (1991). Further validation of the satisfaction with life scale: Evidence for the cross-method convergence of well-being measures. Journal of Personality Assessment, 57, 149-161. 
Duckworth, A.L., Steen, T.A., Seligman, M.E. (2005). Positive psychology in clinical practice. Annual Review of Clinical Psychology, 1, 629-651.

Durak, M., Şenol-Durak, E., Gençöz, T. (2010). Psychometric properties of the satisfaction with life scale among Turkish university students, correctional officers, and elderly adults. Social Indicators Research, 99(3), 413-429. https://doi.org/10.1007/s11205010-9589-4

EC. (2019). Overall life satisfaction in the EU [Online: https://ec.europa.eu/eurostat/statistics-explained/index.php?title=Subjective_wellbeing_-_statistics\#Overall_life_satisfaction_in_the_EU_], Date accessed: Oct. 12, 2021.

Ercan, İ., Ediz, B., Kan, İ. (2004). Sağlık kurumlarında teknik olmayan boyut için hizmet memnuniyetini ölçebilmek amacıyla geliştirilen ölçek. Uludă̆ Üniversitesi Tıp Fakültesi Dergisi, 30(3), 151-157.

Erikson, E.H., Erikson, J.M. (1998). The life cycle completed. WW Norton \& Company.

Erol, M., Yıldırım, İ. (2016). Yükseköğrenim yaşam doyumu ölçeğinin geliştirilmesi. Eğitimde Kuram ve Uygulama, 12(1), 221-243.

Eygü, H., Karaman, S. (2013). Uzaktan eğitim öğrencilerinin memnuniyet algıları üzerine bir araştırma. Kırıkkale Üniversitesi Sosyal Bilimler Dergisi, 3(1), 36-59.

Eygü, H., Kılınç, A. (2020). Yaşam memnuniyeti üzerinde etkili olan faktörlerin araştırılması: Kayseri ili örneği. OPUS Uluslararası Toplum Araştırmaları Dergisi. 16(29), 3591-3618. https://doi.org/10.26466/opus.791217

Field, A. (2017). Discovering statistics using IBM SPSS statistics. Sage.

Gefen, D., Straub, D.W., Boudreau, M. (2000). Structural equation modeling and regression: Guidelines for research practice. Communications of The Association for Information Systems, 4(7), 1-78.

Genç, A., Karaman, F. (2019). Üniversite öğrencilerinde sağlıklı yaşam becerileri ölçeğinin geliştirilmesi. IGUSABDER, 7, 656-669. https://doi.org/10.38079/igusabder.496557

Güllüpınar, F. (2017). Kamusallığın çöküşü ve bireyin sorumlulaştırılması olarak yaşam boyu öğrenme: Eğitim ve istihdam politikalarının eleştirisine bir katkı. Amme İdaresi Dergisi, 50(1), 67-84. 
Güven, S., Şener, A. (2010). Factors affecting life satisfaction in old age. Turkish Journal of Geriatrics, 14(2), 179-186.

Hofstede, G., Hofstede, G.J., Minkov, M. (2010). Cultures and organizations: Software of the mind: Intercultural cooperationand its importance for survival. McGrw-Hill.

Huebner, E.S. (1991). Initial development of the students' life satisfaction scale. School Psychology International, 12, 231-240.

Kaba, İ., Erol, M., Güç, K. (2018). Yetişkin yaşam doyumu ölçeğinin geliştirilmesi. Anadolu Üniversitesi Sosyal Bilimler Dergisi, 18(1), 1-14. https://doi.org/10.18037/ausbd.550232

Karagöz, Y., Doğan, A., Koçyiğit, S. (2016). Gelir düzeyinin hayat kalitesi ve memnuniyetine etkisi: Sivas ilinde ampirik bir uygulama. C.Ü. Íktisadi ve İdari Bilimler Dergisi, 17(1), 168-186.

Kaya, Ö. (2011). Öğrenci yaşam doyum ölçeğinin Türkçeye uyarlanması: Geçerlik ve güvenirlik çalışmaları. KHO Bilim Dergisi, 21(2), 173-185.

Korkmaz, M., Germir, H.N., Yüce, A.S., Gürkan, A. (2015). Yaşam memnuniyeti üzerinde etkili olan sosyo-demografik bileşenler üzerine bir analiz. Uluslararası Hakemli Psikiyatri ve Psikoloji Araştırmaları Dergisi, 2(3), 78-111.

Korukoğlu, A. (2003). Üniversite öğrencilerinin eğitimden beklentileri Ege Üniversitesi İ.İ.B.F. örneği. Süleyman Demirel Üniversitesi İktisadi ve İdari Bilimler Fakültesi Dergisi, 8(1), 79-89.

Köker, S. (1991). Normal ve sorunlu ergenlerin yaşam doyumu düzeyinin karşılaştırılması. Yayımlanmamış yüksek lisans tezi, Ankara Üniversitesi, Ankara.

Lavallee, L.F., Hatch, P.M., Michalos, A.C., McKinley, T. (2007). Development of the contentment with life assessment scale (CLAS): Using daily life experiences to verify levels of self-reported life satisfaction. Social Indicators Research, 83(2), 201-244. https://doi.org/10.1007/s11205-006-9054-6.

Lightsey Jr, O.R., McGhee, R., Ervin, A., Gharghani, G. G., Rarey, E.B., Daigle, R.P., et al. (2013). Self-efficacy for affect regulation as a predictor of future life satisfaction and moderator of the negative affect-life satisfaction relationship. Journal of Happiness Studies, 14(1), 1-18. 
Lyubomirsky, S., King, L., Diener, E. (2005). The benefits of frequent positive affect: does happiness lead to success?. Psychological Bulletin, 131(6), 803-855.

Maddux, J.E. (2018). Subjective well-being and life satisfaction: An introduction to conceptions, theories, and measures. In J. E. Maddux (Eds.), Subjective well-being and life satisfaction (pp. 3-31). Routledge/Taylor \& Francis Group.

Mannell, R.C., Dupuis, S. (2007). Life satisfaction. In J. E. Birren (Ed), Encyclopedia of Gerontology (pp. 73-79). Elsevier Print.

McCamish-Svensson, C., Samuelsson, G., Hagberg, B., Svensson, T., Dehlin, O. (1999). Social relationships and health as predictors of life satisfaction in advanced old age: Results from a Swedish longitudinal study. The International Journal of Aging and Human Development, 48(4):301-324.

Mcdonald, R.P., Ho, R.H. (2002). Principles and practice in reporting structural equation analyses. Psychological Methods, 7, 64-82.

Mowrer, R., Parker, K. (2004). Revised multicultural perspective index and measures of depression, life satisfaction, shyness, and self-esteem. Psychological Reports, 95, $1227-1228$.

Myers, D.G. (2000). The funds, friends, and faith of happy people. American Psychologist, $55,56-67$.

Neugarten, B.L., Havighurst, R.J., Tobin, S. (1961). The measurement of life satisfaction, Journal of Gerontology, 16(2), 134-143. https://doi.org/10.1093/geronj/16.2.134.

OECD. (2021). OECD better life index life satisfaction [Online: https://www.oecdbetterlifeindex.org/topics/life-satisfaction/], Date accessed: Oct. 12, 2021.

Özberk Ünsal, E.B. (2017). Adalet Bakanlığı ceza infaz kurumları personeli eğitim merkezlerinde kullanılmak üzere bir ölçek geliştirme çalışması: Eğitim Memnuniyeti Ölçeği. İnönü Üniversitesi Eğitim Fakültesi Dergisi, 18(1), 70-82.

Özdamar, K. (2016). Ölçek ve test geliştirme yapısal eşitlik modellemesi. Eskişehir: Nisan Kitabevi. 
Paolini, L., Yanez, A.P., Kelly, W.E. (2006). An examination of worry and life satisfaction among college students. Individual Differences Research, 4(5), 331-339.

Pavot, W., Diener, E., Suh, E. (1998). The temporal satisfaction with life scale. Journal of Personality Assessment, 70, 340-354.

Ramachandran, R., Radhika, R. (2012). SocioEconomic statüs, life satisfaction culturel perspective: The elderly Japon and India. International Journal of Humanities and Social Sicence, 2(16): 285-292.

Rojas, M. (2006). Life satisfaction and satisfaction in domains of life: Is it a simple or a simplified relationship?. Journal of Happiness Studies, 7(4), 467-497. https://doi.org/10.1007/s10902-006-9009-2

Schyns, P. (2002). Wealth of nations 1ndividual 1ncome and life satisfaction in 42 countries: A multilevel approach. Social Indicators Research, 60, 5-60.

Sousa, L., Lyubomirsky, S. (2001). Life satisfaction. In J. Worell (Eds.), Encylopedia of women and gender: sex similarities and differences and the impact of society on gender (Volume:2, pp. 667-676). Academic Press.

Şahin, A.E. (2009). Eğitim fakültesinde hizmet kalitesinin Eğitim Fakültesi Öğrenci Memnuniyet Ölçeği (EF-ÖMÖ) ile değerlendirilmesi. Hacettepe Üniversitesi Ĕ̆itim Fakültesi Dergisi, 37 (37) , 106-122.

Şahin, E., Göral, M., Demirel, M., Demirel, D.H., Arslan, F. (2014). Spor bilimleri fakültelerinde öğrenim gören öğrencilerin eğitim hizmetlerine ilişkin doyum düzeylerinin belirlenmesi. Turkish Journal of Education, 3(2), 38-45. https://doi.org/10.19128/turje.181080

Şeker, M. (2011). İstanbul'da yaşam kalitesi araştırmast. İstanbul: İstanbul Ticaret Odası Yayınları, İstanbul'a Yönelik Araştırmalar, 2010-103.

Tabachnick, B.G., Fidell, L.S. (2007). Using multivariate statistics. Pearson.

Taşdelen-Karçkay, A. (2016). Family life satisfaction scale - Turkish version: Psychometric evaluation. Social Behavior and Personality, 44(4), 631-640. https://doi.org/10.2224/sbp.2016.44.4.631

Tezer, E. (1996). Evlilik ilişkisinden sağlanan doyum: Evlilik Yaşamı Ölçeği. Psikolojik Danışma ve Rehberlik Dergisi, 2(7), 1-7. 
Tinsley, H. E., Tinsley, D. J. (1987). Uses of factor analysis in counseling psychology research. Journal of Counseling Psychology, 34(4), 414-424.

Tuzgöl-Dost, M. (2005). Öznel İyi Oluş Ölçeği'nin geliştirilmesi: Geçerlik ve güvenirlik çalışması. Türk Psikolojik Danışma ve Rehberlik Dergisi, 3(23), 103-111.

TÜİK. (2021). Yaşam memnuniyeti araştırmas1, 2020, Haber bülteni, No: 37209. [Online: https://data.tuik.gov.tr/Bulten/Index?p=Life-Satisfaction-Survey-2020-37209], Date accessed: Sept. 15, 2021).

Ünal, L.I. (2013). Kapitalist toplumda eğitim: Kuram ve gerçekliğe genel bir bakış. Praksis, $33(3), 9-27$.

Ünsal, P. Özalp Türetgen, İ. (2005). Bir iş doyumu ölçeği geliştirme çalışması. Yönetim, $16(51), 43-55$.

Vanderweele, T.J. (2017). On the promotion of human flourishing. PNAS, 114(31), 81488156. https://doi.org/10.1073/pnas. 1702996114

Veenhoven, R. (1996a). The study of life satisfaction. In Saris, W.E., Veenhoven, R., Scherpenzeel, A.C. \& Bunting B. (Eds), A comparative study of satisfaction with life in Europe. Eötvös University Press.

Veenhoven, R. (1996b). Developments in satisfaction-research. Social Indicators Research, $37,1-46$.

Watson, D., Clark, L.A., Tellegen, A. (1988). Development and validation of brief measures of positive and negative affect: The PANAS scales. Journal of Personality and Social Psychology, 54, 1063-1070.

Yetim, B., Çelik, Y. (2020). Türkiye'de yaşam kalitesini ne öngörüyor: Ülkeyi temsil eden bir çalışmanın sonuçları. Toplumda Sağlık ve Sosyal Bakım, 28(2), 431-438.

Yetim, Ü. (1993). Kişisel projelerin organizasyonu ve örüntüsü açısından yaşam doyumu. Unpublished Doctoral Thesis, Ege University, İzmir.

Zabriskie, R.B., Ward, P.J. (2014). Satisfaction with family life scale. Marriage \& Family Review 49(5), 446-463. https://doi.org/10.1080/01494929.2013.768321 